ISABELLE ELIAS

ENSAIO SOBRE O USO DA TERMOGRAFIA INFRAVERMELHA NA AVALIAÇÃO DA VITALIDADE PULPAR IN VIVO 


\section{Isabelle Elias}

Ensaio sobre o uso da termografia infravermelha na avaliação da vitalidade pulpar in vivo

Dissertação apresentada à Faculdade de Odontologia da Universidade de São Paulo, para obter Título de Mestre, pelo Programa de PósGraduação em Ciências Odontológicas.

Área de Concentração: Endodontia.

Orientador: Prof. Dr. Celso Luiz Caldeira

São Paulo 
Catalogação-na-Publicação

Serviço de Documentação Odontológica

Faculdade de Odontologia da Universidade de São Paulo

Elias, Isabelle

Ensaio sobre o uso da termografia infravermelha na avaliação da vitalidade pulpar in vivo / Isabelle Elias; orientador Celso Luiz Caldeira. -- São Paulo, 2008.

95p.: tab., fig.; $30 \mathrm{~cm}$.

Dissertação (Mestrado - Programa de Pós-Graduação em Ciências Odontológicas. Área de Concentração: Endodontia) -- Faculdade de Odontologia da Universidade de São Paulo.
1. Termografia
2. Endodontia
3. Diagnóstico por imagem

CDD 617.6342

BLACK D24

AUTORIZO A REPRODUÇÃO E DIVULGAÇÃO TOTAL OU PARCIAL DESTE TRABALHO, POR QUALQUER MEIO CONVENCIONAL OU ELETRÔNICO, PARA FINS DE ESTUDO E PESQUISA, DESDE QUE CITADA A FONTE E COMUNICADA AO AUTOR A REFERÊNCIA DA CITAÇÃO.

São Paulo,

Assinatura:

E-mail: 


\section{FOLHA DE APROVAÇÃO}

Elias I. Ensaio sobre o uso da termografia infravermelha na avaliação da vitalidade pulpar in vivo [Dissertação de Mestrado]. São Paulo: Faculdade de Odontologia da USP; 2008.

São Paulo, ___ I _ _

\section{Banca Examinadora}

1) $\operatorname{Prof}(a) \cdot \operatorname{Dr}(a)$

Titulação:

Julgamento:

Assinatura:

2) $\operatorname{Prof}(a) \cdot \operatorname{Dr}(a)$.

Titulação:

Julgamento:

Assinatura:

3)Prof(a). Dr(a)

Titulação:

Julgamento:

Assinatura: 


\section{DEDI CATÓRI A}

Aos meus pais Edmir e Lourdes....

...que não mediram esforços para que eu chegasse até aqui...

Aos meus irmãos e padrinhos Eliane e Marcelo...

...que nunca souberam me dizer não...

A minha irmã Cristiane...

... pelo carinho e cumplicidade durante toda minha vida...

Aos meus cunhados Paulo, Douglas e Tatiana...

... pelo companheirismo...

As minhas sobrinhas Kiara, Isadora e Maria Eduarda...

... Não há nada mais acolhedor do que o sorriso de uma criança...

A vocês, pessoas tão importantes na minha vida

Dedico este trabalho

Isabelle 


\section{AGRADECI MENTOS}

Primeiramente, agradeço a Deus por mais uma oportunidade.

Considerando esta dissertação como resultado de uma caminhada que não iniciou na FOUSP, agradecer pode não ser tarefa fácil, nem justa.

Para não correr o risco da injustiça, agradeço de antemão a todos que de alguma forma passaram pela minha vida e contribuíram para a construção de quem sou hoje. E agradeço, particularmente, a algumas pessoas pela contribuição direta na construção deste trabalho:

Ao meu orientador prof. Dr. Celso Luiz Caldeira, por partilhar comigo todo o processo de produção da dissertação, desde o projeto de pesquisa, sendo minha mais importante fonte de apoio. Não tenho palavras pra agradecer a amizade, cumplicidade, confiança e enorme paciência. 


\section{Ao prof. Dr. Giulio Gavini...}

...Àquele que quando deveria ser simplesmente professor, foi mestre, transmitindo seus conhecimentos e experiências; que quando deveria ser mestre foi amigo e em sua amizade me compreendeu e incentivou a seguir meu caminho, expresso o meu agradecimento e o meu profundo respeito, que sempre serão poucos diante do muito que foi oferecido!

Meus sinceros agradecimentos Ao prof. Dr. Antonio Carlos Bombana pela recepção, atenção e primeiras orientações no mestrado.

A amiga profa. Ms. Dirce Akemi Sacaguti Kawakami, por acreditar no meu esforço e trabalho, por me transmitir sua experiência e seus conhecimentos, além de suportar meus momentos de estresse durante o curso de especialização e ser minha fonte de inspiradora para o ingresso no curso de mestrado. 
A profa. Dra. Denise Maria Zezell pela presteza, orientação e concessão do equipamento que viabilizou esta pesquisa.

A prof ${ }^{a}$. Dra. Patrícia Ferrari, pela atenção e disponibilidade para analisar e discutir os resultados desse estudo em tão pouco tempo. Obrigada pelas sugestões e conhecimentos compartilhados!

Aos meus colegas e amigos do curso de pós-graduação da Faculdade de Odontologia da Universidade de São Paulo: Gabriella Guimarães, Guilherme Figueiredo, Thiago Brum, Daniela Rossatto, Cristiany Castro, Andreza Isaías, César Brisighello, Carla Gury, Eliane Ribeiro, Cláudia Carreira, Luciano Cardoso, Karla Baumotte, Leonardo Gonçalves... Cada um, a seu modo, contribuiu para que eu pudesse encontrar a força e o incentivo necessários para transpor os obstáculos e as dificuldades inerentes a um trabalho como este. 
Aos atuais e ex-membros da disciplina de Endodontia da Faculdade de Odontologia da UNISANTA: Érico de Mello Lemos, Danilo Minor Shimabuko, Alexandre Gomes Bezerra, Eduardo Akisue, Maurílio Malavasi, Jacob Huli, Paulo Bonfim, Eduardo Calil, Kali de Fátima Amaral, Carmo Aun, Thiago Brum, Luciana Zaher, Juliana Felca, Marcela Santana, Giovanna Ayala, Bruna Nunes, Gustavo Rubino, Felipe Ferreira e Alexandra Barbato... Pelo carinho e presença constante.

A todos os meus queridos amigos e amigas, pelo apoio durante o período da minha pós-graduação, por respeitarem e entenderam minha ausência em certos momentos. Obrigada por existirem em minha vida.

Aos professores e funcionários da disciplina de Endodontia da Universidade de São Paulo. 
Aos funcionários e mestrandos do CLA do I PEN, em especial ao Thiago pela atenciosa e prestativa ajuda na análise dos dados. Obrigada.

\begin{abstract}
A bibliotecária Vânia M. B. de Oliveira Funaro e todos os funcionários da biblioteca da FOUSP e SDO pela correção e formatação da pré-dissertação com agilidade e perfeição.
\end{abstract}

Por fim, é indispensável o agradecimento a CAPES e, novamente, aos meus pais, pelo providencial apoio financeiro concedido durante este trabalho. 
Pode ser que um dia deixemos de nos falar...

Mas, enquanto houver amizade,

Faremos as pazes de novo.

Pode ser que um dia o tempo passe...

Mas, se a amizade permanecer,

Um de outro se há-de lembrar.

Pode ser que um dia nos afastemos...

Mas, se formos amigos de verdade,

A amizade nos reaproximará.

Pode ser que um dia não mais existamos...

Mas, se ainda sobrar amizade,

Nasceremos de novo, um para o outro.

Pode ser que um dia tudo acabe...

Mas, com a amizade construiremos tudo novamente,

Cada vez de forma diferente.

Sendo único e inesquecível cada momento

Que juntos viveremos e nos lembraremos para sempre.

Há duas formas para viver a sua vida:

Uma é acreditar que não existe milagre.

A outra é acreditar que todas as coisas são um milagre. 
Elias I. Ensaio sobre o uso da termografia infravermelha na avaliação da vitalidade pulpar in vivo [Dissertação de Mestrado]. São Paulo: Faculdade de Odontologia da USP; 2008.

\section{RESUMO}

Atualmente, sabe-se que determinar a vitalidade pulpar testando apenas a sua resposta sensorial nervosa, através de testes térmicos ou elétricos, é discutível, pois tais procedimentos não são suficientemente sensíveis para determinar, em definitivo, o real grau de envolvimento pulpar. Além disso, a vitalidade da polpa não depende apenas de seu suprimento nervoso, mas de seu suprimento sanguíneo. Outro fator a considerar com relação ao diagnóstico pulpar, deve-se à possibilidade da ocorrência de respostas pouco confiáveis em pacientes excessivamente ansiosos ao tratamento odontológico, independente do estímulo empregado e da intensidade do teste. $\mathrm{O}$ diagnóstico da vitalidade pulpar através de meios de mensuração da temperatura da coroa do dente, como a termografia infravermelha, que avalia a distribuição de temperatura num corpo através da radiação emitida pela sua superfície, surge como possibilidade para superar as desvantagens dos testes de sensibilidade, como a necessidade da estimulação, as variáveis decorrentes da espessura de dentinaesmalte dos dentes, a idade dos pacientes, a condição da estrutura dentária, entre outras. Esta pesquisa verificou a aplicabilidade da imagem infravermelha na análise da queda de temperatura produzida pelo teste térmico com gás refrigerante e a viabilidade como recurso semiotécnico para diagnóstico endodôntico. Para tal, foram analisados quatro dentes portadores de polpa vital e dois dentes tratados endodonticamente. A metodologia utilizada avaliou, através da imagem térmica, a temperatura da superfície coronária submetidos à queda de temperatura, com e sem 
a utilização do isolamento absoluto. Os resultados não mostraram diferença significante entre os dentes estudados, no que diz respeito à temperatura da superfície coronária e que a utilização do isolamento absoluto também não alterou os resultados. A metodologia proposta neste estudo mostrou-se altamente eficaz para a análise de mudanças térmicas na superfície dentária. No entanto, novos estudos devem ser realizados para que a termografia infravermelha possa se tornar um recurso viável para utilização em Endodontia.

Palavras-chave: Termografia, Endodontia, Diagnóstico 
Elias I. The use of infrared thermographic imaging for pulp vitality evaluation in vivo [Dissertação de Mestrado]. São Paulo: Faculdade de Odontologia da USP; 2008.

\begin{abstract}
Nowadays, it is known that the determination of the pulp vitality testing only its nerve sensorial response through thermal or electrical tests is discussable because those procedures are not sufficiently sensitive to determine the degree of pulp involvement. Besides the vitality of the pulp does not only depend on its nerve condition, but on its blood supply too. Another factor to consider during the pulp diagnostic, independently of the nature of stimulus or their intensity, is the possibility to occur non reliable responses in excessively anxious patients face to the dentistry treatment. The diagnosis of the pulp vitality by the measurement of the dental crown temperature such as the infrared thermography (which evaluates the temperature distribution in a body through the radiation emitted by its surface) arises as a possibility to overcome the sensitivity tests disadvantages, for example: the stimulation necessity, the variants due to the thickness of the dentin and enamel, the age, the condition of the dental structure and etc. This study evaluated the applicability of the infrared thermography test in the analysis of temperature's decline produced by thermal test using cold spray, and its viability as an aid for the endodontic diagnostic. Using thermal imaging, this methodology analyzed the temperature of the crown's surface of four teeth with vitality and two endodontically treated teeth when submitted to the cold test with and without the use of rubber dam. The results did not show a significant difference between teeth conditions with regard to the crown's surface temperature and the use of rubber dam did not affect these results. The proposed methodology used in this study showed to be highly efficient to analyzing the thermal
\end{abstract}


changes on the dental surface; however new studies must be performed to turn infrared thermography a practicable aid into the endodontic practice.

Keywords: Thermography, Endodontic, Diagnosis. 


\section{LISTA DE ILUSTRAÇÕES}

Figura 4.1 - Termovisor ThermaCAM SC 3000

Figura 4.2 - Imagem termográfica do dente 11 portador de polpa vital logo após a aplicação do estímulo térmico, com a utilização do isolamento absoluto

Figura 4.3 - Imagem termográfica do dente 11 portador de polpa vital logo após a aplicação do estímulo térmico, sem a utilização do isolamento absoluto.

Gráfico 5.1 - Variação de temperatura de todos os dentes analisados sem a utilização de isolamento absoluto quando da aplicação do gás refrigerante.

Gráfico 5.2 - Variação de temperatura de todos os dentes analisados com a utilização de isolamento absoluto quando da aplicação do gás refrigerante.

Gráfico 5.3 - Relação tempo/temperatura $(\Delta \mathrm{T}) \mathrm{com}$ a utilização de isolamento absoluto em um incisivo lateral tratado endodonticamente.

Gráfico 5.4 - Relação tempo/temperatura $(\Delta \mathrm{T})$ com a utilização de isolamento absoluto em um incisivo lateral com vitalidade pulpar. 


\section{LISTA DE ABREVIATURA E SIGLAS}

FLD Fluxometria Laser Doppler

FPA Focal Plane Array

mm Milímetro

nm Nanômetro

DDM Diclorodifluorometano 


\section{SUMÁRIO}

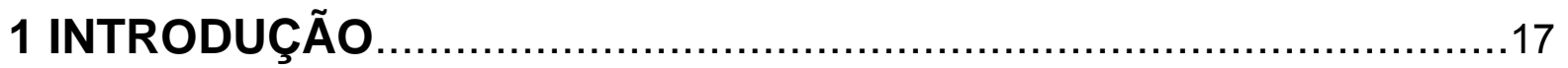

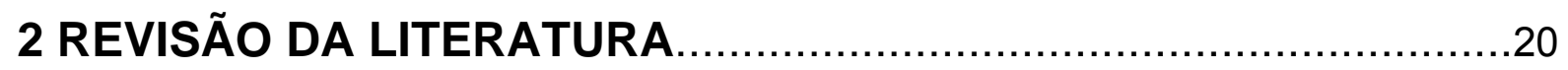

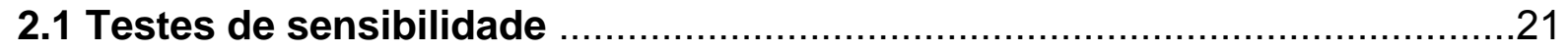

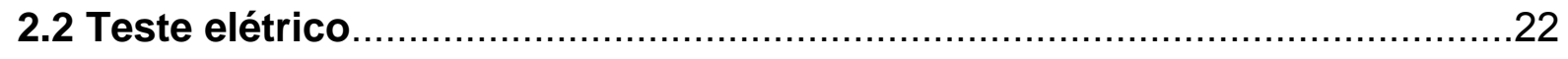

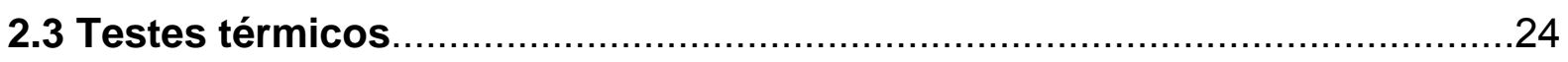

2.4 Comportamento fisiológico da polpa..............................................33

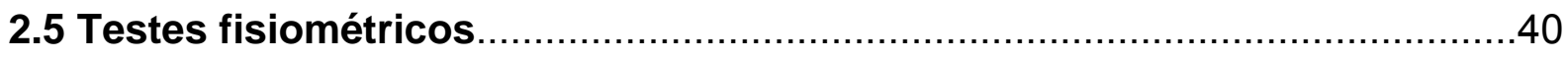

2.6 Avaliação diagnóstica através da mensuração de temperatura ...................48

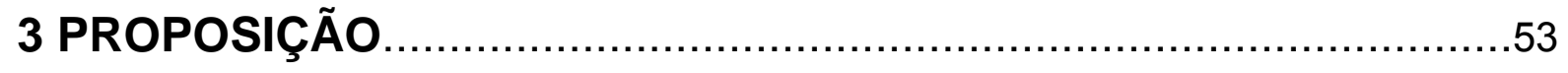

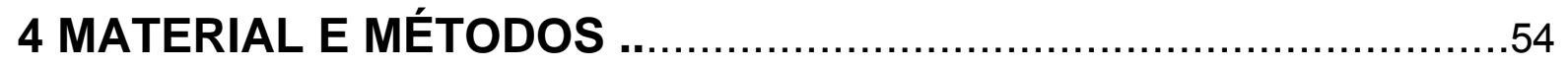

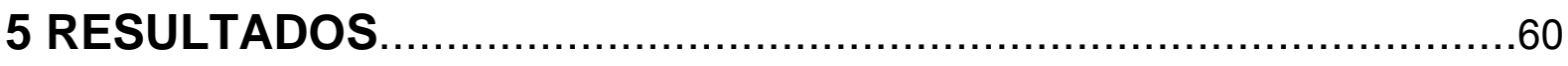

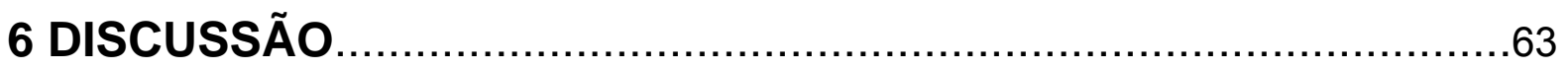

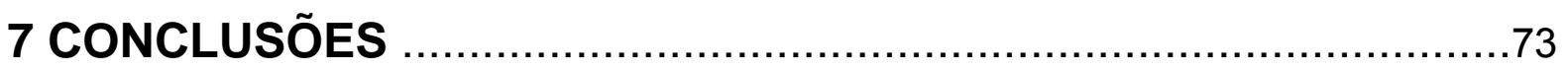

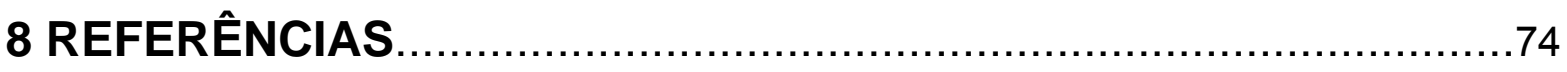

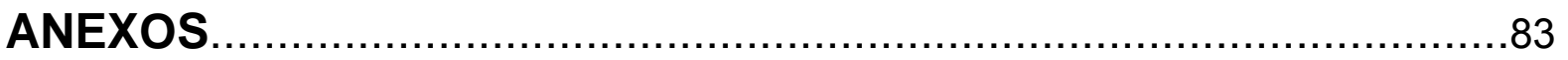

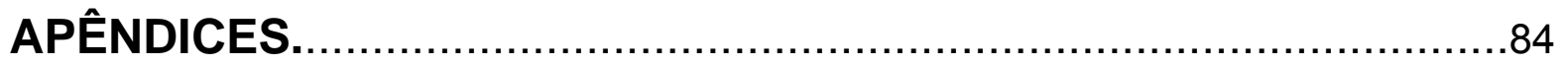




\section{INTRODUÇÃO}

O diagnóstico é de fundamental importância na Endodontia para determinação do tratamento a ser realizado, sendo definido como a arte de identificar uma doença a partir dos seus sinais e sintomas, pois é baseado essencialmente na interpretação ponderada dos dados obtidos com o exame do paciente.

A verificação da vitalidade pulpar estabelece certos conceitos muito particulares, necessários à sua interpretação, essencialmente no que se refere ao conhecimento dos aspectos de normalidade e das modificações que ocorrem na estrutura dentária e, em decorrência, amiúde no complexo pulpar.

A correta realização das manobras que envolvem a determinação da vitalidade pulpar está condicionada ao método de aplicação dos testes de vitalidade e às limitações clínicas que cada recurso auxiliar apresenta.

Os métodos mais comumente utilizados de avaliação da vitalidade pulpar incluem estimulação térmica, seja com frio ou calor. A guta-percha aquecida foi, durante algum tempo, um recurso bastante empregado, sendo que tal teste sempre foi implacavelmente criticado, não obstante à possibilidade de ocorrência de resultados falso-negativos, também à dificuldade em controlarmos a temperatura, gerando relatos de dor intensa quando o calor é aplicado em altas temperaturas.

Dentre os testes térmicos, ressalta-se a utilização do lápis ou bastão de gelo que, há muito, vem sendo o teste mais empregado no cotidiano do consultório odontológico. Apesar disso, com a otimização dos gases refrigerantes 
diclorodifluorometano e tetrafluoretano, agentes que promovem um decréscimo acentuado da temperatura na superfície dentária, estabeleceu-se uma maior confiança nestes testes quanto à avaliação clínica da polpa.

De início, deve-se esclarecer que, lamentavelmente, as respostas obtidas aos ditos testes pulpares, em muitas situações, são discutíveis ou indefinidas.

Encontram-se ainda, como recurso semiotécnico, os chamados testes elétricos, onde ocorre a passagem de corrente elétrica pelo dente. No entanto, sabese que o teste elétrico está condicionado a limitações e variáveis relacionadas tanto ao aparelho como ao próprio paciente.

Cabe considerar que, determinar a vitalidade pulpar testando apenas a sua resposta sensorial nervosa é discutível. Tal procedimento não é bastante sensível para determinar em definitivo o real grau de envolvimento pulpar, pois a vitalidade da polpa não depende apenas de seu suprimento nervoso, mas também de seu suprimento sanguíneo.

A área de pesquisa da fisiologia pulpar está se desenvolvendo rapidamente, e têm surgido recursos que podem mensurar a corrente sanguínea, no lugar da excitação sensorial. Tais recursos são denominados fisiométricos, pois visam determinar o fluxo sanguíneo do tecido que está sendo examinado sendo, portanto, menos sujeitos às limitações e variáveis que envolvem os testes de sensibilidade pulpar.

Dentre os testes fisiométricos podemos relacionar a espectrofotometria, a fotopletismografia, reflexão óptica, fluxometria a laser e a oximetria de pulso. Nesse grupo, podemos citar ainda a termografia infravermelha onde se avalia a distribuição de temperatura num corpo através da radiação emitida pela sua superfície. 
O diagnóstico da vitalidade pulpar através de meios de mensuração da temperatura da coroa do dente parece superar todas as desvantagens inerentes aos testes térmicos e elétricos, como a necessidade da estimulação, as variáveis decorrentes da espessura de dentina-esmalte dos dentes, a idade do paciente, a condição da estrutura dentária, entre outras.

A termografia infravermelha tem sido usada esporadicamente na área médica e odontológica desde a década de 60 e desde então essa metodologia vem encontrando aplicações na Periodontia, Dentística e em estudos das dores orofaciais.

Neste rumo e, em vista da evolução tecnológica dos recursos utilizados no diagnóstico, cabe avaliar a aplicabilidade da imagem infravermelha como recurso semiotécnico para diagnóstico odontológico, especificamente em Endodontia. 


\section{REVISÃO DE LITERATURA}

A terapia endodôntica inicia-se com a fase de diagnóstico, que envolve uma seqüência de passos que orientam e definem a condução do tratamento.

Em 1963, Robinson publica que o diagnóstico em Odontologia pode ser definido como o processo em que os dados obtidos do questionário, exames e testes são combinados pelo cirurgião-dentista para identificar desvios da normalidade. O correto diagnóstico é a base para uma terapia racional e é o primeiro passo para um adequado tratamento.

Seguindo a mesma linha de raciocínio, mas direcionando para os casos com envolvimento endodôntico, em 1970, Baume afirma que a indicação apropriada para a instituição desta terapia depende das causas, dos efeitos e da dinâmica da fisiopatologia pulpar, bem como da sintomatologia presente, sendo a base para o estabelecimento de qualquer diagnóstico diferencial.

No ano de 1977, Ehrmann salienta a importância da realização dos testes de vitalidade ao dizer que nenhum exame bucal estará completo sem que os testes de vitalidade pulpar sejam realizados em todos os dentes.

Além disso, afirma que, antes de qualquer procedimento operatório em um dente, é de importância fundamental ter certeza se este possui viabilidade pulpar ou não.

Estrela (2004) afirma que a mensuração e a interpretação da dor produzida pelos diferentes estímulos pulpares é complexa e difícil, pois, de paciente para paciente, em estado característico de normalidade, a percepção da dor, 
representada pela quantidade de estímulo aplicado para sua indução é diferente e influenciada por vários fatores.

Portanto, a busca por métodos que permitam avaliar confiavelmente a condição pulpar é condição essencial.

\subsection{Testes de sensibilidade}

Acorde Hyman e Cohen (1984), a determinação da vitalidade pulpar necessita de procedimentos semiotécnicos próprios, visando estimular a resposta pulpar, tendo em vista o meio utilizado, lembrando que a interpretação desta resposta depende da revisão dos dados coletados.

Entre os recursos que auxiliam nesta tomada diagnóstica inicial, os mais frequentemente utilizados são os testes térmicos, que produzem na superfície do dente uma alteração de temperatura capaz de gerar uma resposta sensorial por parte do paciente, ou ainda, os testes elétricos realizados através de estimulação elétrica na superfície dentária promovendo uma sensibilização direta das fibras nervosas sensoriais.

Para consolidar a opção por métodos mais modernos, cabe no momento inicial revisar os recursos mais usuais e analisar suas vantagens e desvantagens. 


\subsection{Teste elétrico}

Muito importa relatar o comportamento dos testes disponíveis como recurso complementar à determinação da vitalidade pulpar.

O emprego da excitação elétrica no diagnóstico clínico da polpa pode-se considerar tão antigo quanto o uso dos raios $\mathrm{X}$, haja vista os estudos realizados por Chambers (1982) ao induzir corrente elétrica ao dente na busca de sinais cariosos, e Reynolds (1966) ao determinar a vitalidade ou não dos dentes. Apesar desse fato, os estudos com estimulação elétrica começaram a ter maior aceitação na comunidade científica somente a partir das experiências neurofisiológicas de Bjorn ${ }^{1}$ (1946) apud Hietanen e Rantanen (1973), através do qual foi possível obter os fundamentos necessários à realização dos testes em pacientes.

Segundo Ehrmann (1977), os testes elétricos são particularmente efetivos quando utilizados em dentes de pacientes idosos com grande quantidade de dentina secundária ou reparativa e, no acompanhamento da vitalidade pulpar em dentes que sofreram alguma avaria traumática, onde os testes térmicos com gelo mostram-se ineficazes.

Acorde Grayson (1977), com esse tipo de equipamento, ocorre a possibilidade de transferência do estímulo aos dentes adjacentes conduzindo a falsos-positivos.

Ehrmann (1977) relata ainda a impossibilidade de uso em dentes com aparelhos ortodônticos e resposta falso-positiva nos casos de necrose por liquefação.

\footnotetext{
${ }^{1}$ Bjorn, H. Electrical excitation of teeth and its application to dentistry, Svensk Tandlak - T, 1946; 39.
} 
Ainda podemos inferir sobre as diferentes respostas encontradas à aplicação do teste elétrico nos diferentes grupos dentários, em função das variações anátomofisiológicas que são encontradas (BERGER, 1986).

Fuss et al. (1986) ressaltaram as mesmas restrições ao uso do estímulo elétrico e salientam ainda que não é um teste muito confiável nas situações de dentes jovens em fase de rizogênese incompleta.

Schlich e Schlich ${ }^{2}$ apud Aun et al. (1994), comparando a eficácia do DDM com o teste elétrico em dentes restaurados ou cariados, obtiveram respostas positivas em $92 \%$ dos casos com o gás refrigerante, em oposição a $80 \%$ com o estímulo elétrico.

No ano de 2000, Burns e Cohen afirma que o teste elétrico não fornece quaisquer informações acerca do suprimento vascular da polpa, que é o determinante real da vitalidade pulpar. Além disso, inúmeras condições podem produzir respostas falsas aos testes elétricos.

Cave, Freer e Podlich (2002) sugerem cautela na utilização do teste elétrico em pacientes submetidos à ortodontia. O estudo mostra que a resposta ao teste é aumentada quase que instantaneamente quando o dente é submetido a forças ortodônticas e o efeito pode ser prolongado por até 9 meses após a ortodontia. Os autores concluíram que o teste não é adequado para essa situação clínica e indicam o teste térmico com gás refrigerante como método diagnóstico mais seguro para esses pacientes.

Ademais, Mickel et al. (2006) estudaram a condutibilidade elétrica de 31 materiais de uso comum em consultórios como: cera, géis a base de água, anestésicos tópicos, dentifrícios entre outros. O estudo mostra diferenças

\footnotetext{
${ }^{2}$ Schlich E, Schlich K. Experiences using the lege artis thermal test for vitality testing. Quintess Int 1973;(6):25-6.
} 
estatisticamente significantes entre alguns materiais, fato que pode comprometer o diagnóstico de dentes portadores de calcificações, polpas parcialmente mortificadas e também dentes que tenham sofrido trauma recente.

Em vista das inúmeras limitações apresentadas pelos testes elétricos, cabe concentrar nossos esforços em aparatos mais práticos e com menos restrições quanto à sua utilização.

\subsection{Testes térmicos}

As primeiras referências da utilização de testes térmicos datam de $1898 \mathrm{com}$ as pesquisas de Walkhoff ${ }^{3}$, apud Dummer, Hicks e Huws (1980), conceituando o emprego dos testes térmicos e, de 1899, quando Jack colocou água a diferentes temperaturas sobre a superfície dentária até provocar dor no paciente, com a finalidade de graduar a intensidade do estímulo necessário para essa sensibilização.

Com relação aos agentes térmicos que utilizam fontes de calor para denotar resposta pulpar, a guta-percha aquecida foi durante muito tempo, o recurso mais empregado.

Apesar disso, o teste com guta-percha aquecida sempre foi severamente criticado, essencialmente quanto à possibilidade de ocorrerem resultados falsonegativos (LUNDY; STANLEY, 1969) e quanto à dificuldade em controlarmos a temperatura em patamares altos, e, por outro lado, facultando os relatos de dor intensa quando o calor é aplicado em temperaturas muito altas (CHAMBERS, 1982).

\footnotetext{
${ }^{3}$ Walkhoff, O. Bermerkungen zur thermometrie der pulpa. Deutsch Monatsschrift fur Zahnheilkunde. 1898;17:555-7.
} 
Ainda deve-se inferir sobre a possibilidade de resultados falso-positivos serem colhidos quando, em casos de necrose pulpar, o calor produzido pela guta-percha aquecida gerar uma expansão dos gases necróticos intra-pulpares, causando pressão na região periapical, e traduzindo uma resposta dolorosa nada confiável (CHAMBERS, 1982).

Mumford, em 1967, ressalta a ocorrência de formação de gases na necrose da polpa; nesse caso, a aplicação da guta-percha aquecida pode provocar a expansão desses gases, causando dor pela pressão nos tecidos periapicais conduzindo a resultados falso-positivos.

Por sua vez, a utilização do estímulo frio empregando-se "lápis" de gelo como teste de vitalidade pulpar, surgiu em 1941, com o estudo de Austin e Waggener, que atestaram a aplicabilidade do método á época, em função da praticidade de acondicionamento da água em "cones" de alumínios vazios, que, ao congelar, permitia a realização do teste.

Os autores expressam que a resposta ao teste com gelo pode ser dificultada em função da quantidade de dentina secundária formada, ou da presença de restaurações ou coroas metálicas, erosão ou abrasão das superfícies dentárias, presença de pulpite, e quando reconhecidas às diferenças individuais de cada paciente.

À sua vez, Dachi, Haley e Sanders (1967) efetuaram aplicação do "bastão" de gelo em 180 dentes, variando-se os tempos (1, 2, 3, 5, 8,10 e 12 segundos) e realizando os testes em dias alternados para cada dente em particular, com o intuito de dizimar a possibilidade de que alterações de ordem geral, como mudanças na temperatura ambiental e corporal, mascarassem os resultados finais. 
Observaram os autores que, o emprego do teste térmico com frio é extremamente válido, quando respeitado um tempo compreendido entre 5 e 8 segundos de aplicação do gelo, para sensibilizar o dente testado.

Acentuam ainda que, com maior espessura de esmalte e dentina, como os caninos, exigiram uma acuidade maior na realização do teste, em vista de seu comportamento renitente à obtenção de resposta positiva à aplicação do gelo.

Pesce , Medeiros e Risso (1985) aquilataram a eficiência do teste térmico com frio, ao aplicarem o "lápis" de gelo por, no máximo, 10 segundos, em 474 dentes clinicamente íntegros e sadios de 56 pacientes, cuja idade variava entre 10 e 55 anos.

De posse dos resultados, verificam a alta incidência de respostas positivas ao teste, cerca de $85,5 \%$, lembrando ademais que a seleção dos dentes fazia supor que, clinicamente, tratavam-se os mesmos de polpa com vitalidade.

Outro fator relevante referiu-se à porcentagem de respostas negativas, onde dos 69 dentes que não responderam aos testes, 40 deles $(57,97 \%)$ pertenciam aos pacientes da faixa etária entre 10 e 18 anos.

Aliás, a qualificação do teste pelo frio em determinar a vitalidade ou não da polpa dental esclarece-se no fato deste também possibilitar, a partir das respostas obtidas, a apreciação do grau de reversibilidade do processo inflamatório, importante no planejamento do tratamento a ser instituído (MEDEIROS; PESCE, 1980; PAIVA; ANTONIAZZI, 1988).

Neste ponto cabe esclarecer que, a ocorrência de resposta frente aos estímulos térmicos, decorre das variações ocorridas na pressão interna intra-pulpar, 
quando da sensibilização do dente, segundo Beveridge e Brown (1965), e particularmente, quando das alterações de pressão intra-pulpar causadas pela mudança da temperatura em seu interior (VAN HASSEL; BROWN, 1969).

Beveridge e Brown (1965) analisaram o efeito do resfriamento produzido pela aplicação de cloreto de etila, na face oclusal do dente, durante 8 segundos. Observaram um decréscimo da pressão intra-pulpar de $28 \mathrm{mmHg}$ enquanto durava a aplicação, retornando lentamente aos níveis normais após a remoção do agente frio.

Segundo Brannstrom, Linden e Astrom (1967), Pashley (1992), outra forma de manifestação, capaz de produzir resposta aos estímulos térmicos, é a ocorrência de alterações hidráulicas intra-tubulares, causadas pela movimentação proveniente da contração térmica do fluído dentinário, que poderiam ativar os mecanoreceptores mais próximos da polpa.

Ainda sobre o grau de dificuldade desses testes, Pulver e Korzen (1978), em um guia de interpretação das respostas colhidas em vários tipos de testes para diagnóstico em Endodontia, relatam que, na aplicação de teste com gelo, a ausência de resposta pode simplesmente significar resistência ao frio, não indicando necessariamente qualquer anormalidade. O mesmo tipo de situação pode ainda ocorrer quando da aplicação do calor.

Mumford (1984) comparou as respostas fornecidas pela aplicação do frio e calor em 114 dentes que respondiam positivamente ao teste elétrico.

Quatro dentes não responderam ao frio e 12 não responderam ao calor, sendo que os elementos que não responderam a nenhum dos testes eram caninos. O autor justifica a ausência de resposta devido ao volume exagerado de sua coroa e consequentemente sua maior espessura de esmalte e dentina. 
Atualmente o emprego dos aerossóis refrigerantes, proporcionou uma melhoria na avaliação da resposta pulpar, principalmente onde os métodos usuais mostravam-se mais instáveis, como, por exemplo, em dentes permanentes jovens (AUN et al., 1992, 1994), e dentes com grande espessura de esmalte e/ou dentina (CALDEIRA; AUN 1996; MEDEIROS; PESCE, 1993), perfilando hoje em dia, entre os testes mais preciosos e confiáveis na avaliação da vitalidade pulpar (CALDEIRA, 1997).

Extensa literatura descreve os benefícios desse tipo de teste. Graças à iniciativa de Von Eifinger no ano de 1970, iniciou-se o uso específico do gás refrigerante DDM como recurso semiotécnico destinado a determinar a vitalidade pulpar. A partir daí, inúmeros trabalhos testaram os benefícios do gás e da neve carbônica em relação aos testes utilizados até então.

Quanto ao emprego destes gases no diagnóstico clínico da vitalidade pulpar, observa-se que as substâncias refrigerantes, como um todo, ao serem utilizadas na forma de aerossol, invariavelmente promove na superfície dentária um decréscimo acentuado da temperatura, de modo rápido e intenso, e em conseqüência, fornecem respostas mais seguras e confiáveis (AUN et al., 1994).

No que se refere à constatação da alta capacidade refrigerante destes gases, várias pesquisas retratam com propriedade o fato de este teste poder preencher várias lacunas deixadas pelos testes como o gelo, quando este último torna-se incapaz de gerar respostas confiáveis.

Pesce et al. (1995), ao compararem os efeitos do gelo e dos gases refrigerantes (neve carbônica e DDM) na temperatura intra-pulpar, puderam observar que ocorreu decréscimo acentuado desta, uma privação de energia calórica da 
ordem de $4.5^{\circ} \mathrm{C}$ para o gelo, $13^{\circ} \mathrm{C}$ para a neve carbônica $\left(\mathrm{CO}_{2}\right)$ e de $8.5^{\circ} \mathrm{C}$ para o DDM.

Convém admitir, ainda neste sentido, que certamente muitos fatores podem influenciar na resposta pulpar, impedindo a transmissão do estímulo aplicado até os receptores sensoriais da polpa. Dentre estes fatores incluem-se a maior espessura de esmalte e dentina, presença de alterações degenerativas, e mesmo fenômenos reacionais da polpa.

Caldeira et al. (1995) puderam refletir este comportamento à análise clínica, ao avaliarem o número de respostas obtidas à aplicação de diclorodifluorometano e gelo em "bastão", e mensurando radiograficamente a espessura proximal de esmalte e dentina. Para tal, analisaram os dentes de 90 pacientes, divididos em três faixas etárias distintas, 1= 10 a 20 anos, 2= 30 a 40 anos e 3= acima de 55 anos, onde puderam constatar um aumento no número de respostas negativas com o passar da idade, e principalmente nos dentes com maior espessura de esmalte e dentina.

Já, com relação às alterações degenerativas, que modificam as características de normalidade do tecido pulpar, alterando metabolicamente a estrutura da polpa, aumentando o grau de mineralização ou mesmo comprimindo os nervos sensitivos sabemos que podem perturbar certas funções relacionadas à vitalidade desta polpa, dificultando, outrossim, a avaliação dos testes realizados.

Oportuno salientar também que, com o passar da idade, ocorre uma formação progressiva e evidente de dentina peritubular, provocando o fechamento dos túbulos dentinários, principalmente nos casos onde o dente é submetido a estímulos excessivos, como atrições e abrasões (MENDIS; DARLING, 1979), o que pode em 
muito dificultar a transmissão dos estímulos até a unidade neuroreceptora da polpa (WEBER; ZAKI, 1986).

Aun et al., em 1992, com a mesma preocupação realizaram um estudo com vistas a comparar a eficácia de três tipos de testes de vitalidade (gelo, teste elétrico e gases refrigerantes - Frigen e DDM), avaliando clinicamente a resposta pulpar em 40 incisivos centrais e laterais permanentes jovens com rizogênese completa de 12 crianças entre 9 e 11 anos de idade.

A porcentagem de respostas positivas à primeira aplicação foi de $60 \%$ para o "lápis" de gelo, 82,5\% para o teste elétrico, e 95\% para os dois gases refrigerantes testados. À segunda aplicação, efetuada sequencialmente à primeira, resultou em $67,5 \%$ para o gelo, $82 \%$ para o teste elétrico e $100 \%$ para os gases refrigerantes.

Este estudo permitiu-nos ainda uma comparação com outra pesquisa de Aun et al., 1994, onde foram realizadas tomadas de vitalidade pulpar com recursos térmicos (gelo e DDM) e elétrico em 86 incisivos centrais superiores com rizogênese incompleta, de 46 crianças com idade entre 7 e 8 anos, que, através de análise radiográfica, apresentavam ao menos $2 / 3$ de formação radicular.

O número de respostas positivas foi $53(61,6 \%)$ para o gelo, $67(77,9 \%)$ para o teste elétrico e 80 (93\%) para o gás refrigerante DDM, portanto demonstrando uma ligeira diminuição no índice geral de respostas positivas quando comparado aos dentes com rizogênese completa.

Este fato deve-se, segundo Bernick $(1964,1972)$, à incompleta inervação da camada odontoblástica, um dos fatores responsáveis pela sensibilização da unidade neuro-receptora da polpa. 
Considerando ainda as alterações reacionais decorrentes de fenômenos fisiopatológicos, como os traumatismos dentários, nos quais fica patente as diversas modificações do comportamento pulpar, Caldeira e Aun (1996) avaliaram a vitalidade pulpar em 125 casos de traumatismos que foram atendidos de forma emergencial, ou até, após uma semana do acontecido.

Ao compararem as respostas obtidas com "bastão" de gelo e DDM aos 30 e 90 dias decorridos os traumas, puderam constatar que, fraturas de esmalte, ou esmalte e dentina, apresentavam respostas negativas ao gelo da ordem de 30 a $40 \%$ nos dois períodos, e, $100 \%$ de respostas positivas ao gás refrigerante.

Nas fraturas de dentina e cemento, obtiveram os mesmos índices para o gelo e, cerca de $10 \%$ de respostas negativas ao DDM. Nas concussões e subluxações as respostas negativas ao gelo abrangiram $35 \%$ no $1^{\circ}$ mês e $50 \%$ aos 90 dias. Com o gás refrigerante, as respostas negativas foram cerca de $10 \%$.

$\mathrm{Na}$ luxação extrusiva, os índices mostraram apenas $20 \%$ de respostas positivas aos 30 dias com o "bastão" de gelo e nenhum relato de sensibilidade aos 90 dias. Com o refrigerante os autores obtiveram $30 \%$ de respostas positivas no primeiro período e $20 \%$ no segundo.

Na luxação intrusiva, os índices desalentadores foram de $90 \%$ de respostas negativas á aplicação do gelo no $1^{\circ}$ mês e $100 \%$ no $3^{\circ}$ mês, e, à aplicação do DDM foram de $80 \%$ e $100 \%$ de respostas negativas nos dois períodos testados.

Outro fator impedidor da transmissão dos estímulos térmicos está calcado na condição restauradora do dente a ser testado, particularmente quando o mesmo 
apresenta restaurações metálicas ou resinosas extensas, ou ainda, coroas protéticas.

Em decorrência de problemas ambientais - ozônio - atmosfera, o uso de clorofluorcarbonos foi substituído pelo tetrafluoretano, com propriedades termodinâmicas semelhantes ao diclorodifluormetano, e com os requisitos necessários para ser usado como agente de refrigeração na determinação da vitalidade pulpar .

Peterson et al. (1999) avaliaram a habilidade dos testes térmicos (guta-percha aquecida e gás refrigerante) e elétricos para registrar vitalidade pulpar. Salientam a importância da acuidade de um teste diagnóstico, isso é, a sua capacidade de classificar corretamente um caso. Os autores analisaram 59 dentes com estado pulpar desconhecido, mas que precisavam sofrer a terapia endodôntica, e 16 dentes hígidos, cujo exame radiográfico expressava normalidade periapical. No total, 46 dentes tinham vitalidade pulpar e 29 dentes apresentavam a polpa necrosada. Os 59 dentes que necessitavam de terapia endodôntica tiveram suas polpas inspecionadas diretamente, a fim de confirmar a resposta fornecida pelos testes. Determinaram que ambos os métodos revelaram valores falsos positivos ou negativos na faixa de 10 $16 \%$.

Seguindo este raciocínio, Burns e Cohen (2000) afirmam que a ausência de respostas aos testes térmicos indica uma polpa não vital. Entretanto, a ausência de respostas aos testes térmicos pode indicar também uma resposta falso-negativa devido à calcificação excessiva, a um ápice incompletamente formado, a um trauma recente ou à pré-medicação do paciente.

Outro fator a considerar com relação à tomada diagnóstica buscando-se a vitalidade da polpa, deve-se à possibilidade da ocorrência de respostas pouco 
confiáveis em pacientes excessivamente ansiosos ou pavorosos do tratamento odontológico e, particularmente, endodôntico, independente do estímulo empregado e da intensidade do teste.

Através da interpretação dos dados obtidos com testes de sensibilidade pulpar, teremos subsídio para estabelecermos um diagnóstico mais preciso, porém, como foi visto anteriormente, os mesmos estão sujeitos às variações tais como, limiar de sensibilidade do paciente, interpretação da resposta por parte do profissional, além de outros fatores, que podem induzir falsas interpretações dos dados obtidos.

Para que se possa melhor compreender o comportamento da resposta pulpar cabe aqui ressaltar alguns aspectos fisiológicos pulpares, principalmente no que concerne às características peculiares da mesma, e compreender ademais qual o tipo de inferência que estas manifestações fisiológicas podem ter na polpa que dificultam a tomada de uma resposta confiável e abrem caminho para a busca de métodos diagnósticos que apresentem um menor número de variáveis e dificuldades.

\subsection{Comportamento fisiológico da polpa}

Segundo Paiva e Antoniazzi (1988), a polpa é um tecido conjuntivo altamente vascularizado, que, com o desenvolvimento do elemento dental, fica contido numa cavidade de paredes rígidas e inexpansível e dela fazem parte fibras colágenas, elementos celulares, fibras nervosas e vasos sanguíneos. 
A despeito da condição anátomo-fisiológica exposta, no emprego dos testes de vitalidade persiste dúvida quanto ao caminho perseguido pela estimulação, pela qual, a energia aplicada externamente à superfície dentária, principalmente sob a forma de estímulo térmico frio, é convertido em sinais que estimulam a unidade sensorial do dente.

Acorde Brannstrom, Linden e Astrom (1967), Pashley (1992), a teoria mais frequentemente aceita para explicar o comportamento fisiológico da polpa é a teoria hidrodinâmica, pela qual ocorrem alterações hidráulicas intra-tubulares, causadas pela movimentação proveniente da contração térmica do fluído dentinário, que poderiam ativar os mecanoreceptores mais próximos da polpa, e excitar as terminações nervosas das fibras do tipo Delta-A.

Confirma-se tal teoria, quando se observa que, os túbulos dentinários comportam-se como finos tubos capilares, onde, qualquer alteração na superfície dentária, causa um rápido movimento do fluído para a polpa, a estimular as terminações nervosas intrapulpares.

A aplicação de estímulo térmico, principalmente o frio, ao dente produz certamente uma rápida movimentação do fluído dentro dos túbulos dentinários, que se mantêm contraído pela pressão das forças capilares.

Em 1998, Caldeira investigou in vivo a capacidade de transmissão do estímulo térmico frio até a parede vestibular interna. Utilizando-se de termistores, o autor inquiriu sobre a relação existente entre o tempo de resposta obtido durante o teste de sensibilidade pulpar com gás refrigerante tetrafluoroetano e a diminuição da temperatura promovida pelo mesmo na região limítrofe da dentina na câmara pulpar. Foram utilizados 60 dentes anteriores superiores com vitalidade pulpar, e que seriam submetidos ao tratamento endodôntico, de três faixas etárias distintas: 10 a 20 anos, 
21 a 50 anos e acima de 51 anos. A pesquisa compreendeu várias etapas, a saber; tomada de tempo da resposta ao teste de sensibilidade com gás tetrafluoretano, mensuração da espessura do esmalte até a parede vestibular interna, medição da temperatura interna desta face antes e após a aplicação do gás refrigerante e, coleta do tempo até que se inicia a troca de temperatura nesta área. Os resultados refletem a importância da análise da faixa e da espessura medida, em dificultar a transmissão do estímulo frio para a face interna dentinária, influenciando na diminuição da temperatura e no tempo de troca até que ela se manifeste na parede vestibular, ocorrendo com maior significância na faixa etária mais avançada; observou-se ainda que, o tempo de resposta inicial ao teste foi sempre menor àquele obtido até que ocorra a troca da temperatura na parede vestibular da câmara pulpar.

De acordo com Trowbridge et al. (1980), uma redução da temperatura na superfície dentária da ordem de 20 à $30^{\circ} \mathrm{C}$, pode causar uma movimentação de fluído de 3 a 4um.

Outro fator a considerar, segundo Linde (1984), refere-se à quantidade de túbulos dentinários que varia em função da sua localização, visto que há uma diminuição da superfície de dentina próxima à polpa, onde encontramos cerca de 65 mil túbulos por $\mathrm{mm}^{2}$ próximo à polpa e 15 mil próximos à periferia do dente, observando, também os achados de Pashley $(1984,1985)$, demonstrando que a dentina superficial tem menos túbulos por $\mathrm{mm}^{2}$ do que a dentina profunda.

Alguns estudos, como o de Mjor e Nordahl (1996), demonstram que os túbulos dentinários são interligados entre si por um sistema intrínseco de canalículos que partem dos túbulos principais em várias direções, o que poderia dificultar ainda mais a movimentação do fluído tubular e a transmissão do estímulo. 
Com relação à inervação pulpar propriamente dita, tanto fibras nervosas mielínicas como amielínicas são encontradas na polpa.

Segundo Pitt Ford e Rowe (1990), as fibras nervosas amielínicas fazem parte de um sistema simpático que controla a contração e expansão dos vasos sanguíneos. As fibras nervosas sensoriais da polpa, responsáveis pela sensibilização e dor, penetram via forame apical até alcançarem a polpa coronária, onde atingem a área adjacente à camada sub-odontoblástica rica em células, a formar o complexo de Raschkow, onde, alguns pequenos filamentos, podem passar à pré-dentina.

De acordo com Olgart (1986), as fibras amielínicas, tipo C, também detectam a dor, sendo principalmente responsáveis pelos sintomas dos estágios finais da inflamação, apresentando-se inclusive resistentes à fase inicial do processo de necrose, mas as principais fibras nervosas são as mielinizadas, ou seja, as do tipo Delta-A, facilmente estimuladas e que detectam as dores mais fugazes, sendo as responsáveis diretas pela sensibilização quando da aplicação de um estímulo térmico com frio.

Isto reflete em direções diferentes quando se compara a atividade dessas fibras nervosas e dos tecidos que as sustentam com a idade do paciente, seja aquele mais jovem ou mais idoso.

Com relação aos dentes jovens, segundo Bernick (1964, 1972), ocorre na camada odontoblástica uma deficiência de formação, pela precocidade de sua instalação, inabilitando em várias situações a transmissão do estímulo para a unidade receptora sensitiva intrapulpar.

Esta limitação na função sensorial da polpa pôde ser esclarecida no estudo de Fearnhead (1963), ao analisar histologicamente as fibras sensoriais intrapulpares 
em dentes imaturos, observando que esta deficiência perdura até que este dente esteja em função oclusal e mastigatória na cavidade oral por cerca de 4 a 5 anos.

Evidentemente, acorde Fried (1992), em razão da freqüência com que ocorrem tais estimulações, é de se pressupor que ocorra no passar da idade, uma diminuição da capacidade dos nervos pulpares em responder aos estímulos, o que em muito acelera a deterioração do complexo pulpar, essencialmente da função sensitiva.

Bernick (1967), analisou histologicamente os dentes de pacientes com idade acima de 40 anos, constatando uma diminuição do volume da câmara coronária e da quantidade de fibras nervosas e vasos sanguíneos, pressupondo uma íntima relação entre a redução da excitabilidade dos dentes mais senis com os processos fisiopatológicos decorrentes do avançar da idade.

De acordo com Walton e Torabinejad (1997), a polpa madura possui uma rede vascular peculiar e extensa, caracterizada por uma circulação sanguínea do tipo terminal composta por vasos sanguíneos aferentes, eferentes e linfáticos.

Comparativamente a outros tecidos da boca, a polpa tem maior fluxo sanguíneo por unidade de peso. Além disso, o fluxo sanguíneo capilar na região coronária é quase o dobro daquele encontrado na região radicular. O suprimento sanguíneo é regulado por fatores locais bem como pelos nervos simpáticos. Os músculos lisos presentes nos vasos possuem tanto receptores alfa quanto betaadrenérgicos; portanto, eles respondem contraindo-se quando os nervos simpáticos são estimulados ou quando vaso-constritores são injetados na circulação.

A presença de fibras colinérgicas ainda não foi confirmada na polpa, portanto, pode faltar um controle parassimpático nas arteríolas. Sob circunstâncias normais em um dente maduro, o sangue flui através do leito capilar periférico bem 
abaixo da capacidade máxima. Assim, um leito capilar sub-odontoblástico extenso não é predominante quando a polpa é observada sob o microscópio óptico comum. Os capilares tornam-se mais aparentes quando técnicas de pressão e perfusão são utilizadas para a identificação ou quando a polpa encontra-se inflamada.

Quando acometida por algum estado patológico, a polpa lesada parece apresentar uma resposta vascular bifásica. Ela consiste de uma vasoconstrição inicial seguida de vasodilatação com aumento da permeabilidade vascular. Esta fase é a medida por neuropeptídeos liberados pelas fibras aferentes, resultando em um escape de fluído dos vasos e num edema localizado. Este edema pode causar um aumento na pressão tecidual que dá origem, por sua vez, a uma redução no fluxo sanguíneo e na drenagem linfática resultando num aumento da quantidade de dióxido de carbono e acidez. Para compensar, o fluxo vascular na área lesada é alterado pelas derivações arteriovenosas da polpa, as quais redirecionam o fluxo para longe da área inflamada e em direção aos vasos pulpares eferentes. Isto permite uma resolução lenta do edema tecidual e uma restauração do fluxo sanguíneo normal.

Quando acometida por uma lesão severa o suficiente para superar a capacidade de vascularização para compensar o processo, uma isquemia local e uma extensão progressiva da destruição tecidual podem ocorrer.

Uma alteração do fluxo vascular está relacionada com uma alteração de sensibilidade. Uma taxa de fluxo elevada, que pode ocorrer durante certas fases da inflamação, pode contribuir para a redução no limiar doloroso das fibras nervosas delta-A, levando a uma resposta exacerbada aos estímulos térmicos. Por outro lado, a isquemia, induzida pelo fluxo muito reduzido, pode suprimir a atividade dessas 
fibras nervosas mais do que nas fibras do tipo C, levando a alteração na qualidade da experiência dolorosa do paciente.

Os testes de sensibilidade pulpar nem sempre refletem o real grau de envolvimento pulpar, pois, segundo Bhaskar e Rappaport (1973), a vitalidade da polpa depende do seu suprimento sanguíneo e da atividade circulatória, que são indicadores do real estado do tecido pulpar, entretanto, servem como orientação ou apenas como indicação do grau de vitalidade ou não da polpa, através de suas respostas sob certas circunstâncias.

Burns e Cohen (2000) afirmam que apenas impressões generalizadas podem ser obtidas através dos testes térmico e elétrico em dentes traumatizados. Eles são, na verdade, testes de sensibilidade para avaliar a função nervosa e não indicam a presença ou ausência de circulação sanguínea no interior da polpa. Após uma lesão traumática, a capacidade de condução das terminações nervosas ou dos receptores sensoriais está suficientemente desordenada para inibir o impulso nervoso derivado de um estímulo elétrico ou térmico. Isto torna o dente traumatizado vulnerável ás interpretações falso-negativas desses testes. Não se pode admitir ainda, segundo os autores, que os dentes que fornecem um a resposta positiva no exame inicial sejam saudáveis e continuem a fornecer a mesma resposta positiva. Não se pode admitir, por outro lado, que os dentes que produzem uma resposta negativa ou que não produzem resposta tenham polpas necróticas, pois eles podem apresentar resposta positiva mais tarde. Foi demonstrado que até 9 meses podem decorrer para que o fluxo sanguíneo retorne ao normal, numa polpa de um dente completamente formado que tenha sofrido trauma. Quando a circulação é recuperada, a sensibilidade aos testes pulpares retorna. 
Portanto, em vista das inúmeras dificuldades encontradas na determinação do estado da polpa, parece salutar a busca por avaliar o suprimento sanguíneo do tecido pulpar através dos testes ditos fisiométricos, os quais visam mensurar o fluxo sanguíneo através da aplicação de um determinado comprimento de luz sobre o tecido examinado, determinando a condição de oxigenação do mesmo, sendo, portanto, menos sujeitos às limitações e variáveis que envolvem os testes de sensibilidade pulpar.

\subsection{Testes fisiométricos}

Para melhor compreender o comportamento desses testes cabe aqui ressaltar algumas características e relatos da utilização dos principais testes utilizados na determinação da vitalidade pulpar. Os testes fisiométricos são utilizados em larga escala na medicina, principalmente a fluxometria a laser que busca avaliar a microcirculação sanguínea de um determinado tecido.

O primeiro relato da utilização da Fluxometria Laser Doppler (FLD) foi em 1972 com Riva e teve a finalidade de detectar fluxo sanguíneo na retina de coelho. Esta tecnologia foi desenvolvida para medir fluxo sanguíneo em sistemas microvasculares intactos como a retina, córtex renal e pele, com inúmeras aplicações na Medicina (BOGGETT; BLOND; ROLFE 1985).

Em 1986, Gazelius, Olgart e Edwall apresentaram um método não invasivo para determinação do fluxo sanguíneo pulpar denominado fluxometria a laser (Laser Doppler), o qual produz uma luz laser de Hélio-Neon de comprimento de onda 
conhecido, que é emitida para o tecido analisado através de uma sonda de fibra óptica. Quando a luz atravessa o tecido, uma parte é absorvida e outra é refletida pelo mesmo, sendo que a luz refletida divide-se em dois componentes, um refletido dos tecidos estáticos, que possuem o mesmo comprimento de onda da luz emitida, e um segundo componente que é a luz refletida pelas células sanguíneas em movimento, que produzem um comprimento de onda diferente. As luzes são posteriormente captadas por um fotodetector onde são transformadas em um sinal elétrico que é transmitido e processado por um programa computacional específico, produzindo um valor de fluxo sanguíneo.

Por sua vez, Wilder-Smith (1988), mediu o fluxo sanguíneo pulpar através da fluxometria a laser em diferentes situações clínicas e pôde observar que dependendo da injúria estabelecida pela cárie dental, pode ocorrer mudança significativa na velocidade do fluxo.

Com relação à determinação do fluxo sanguíneo pulpar, através do Laser Doppler, em dentes que sofreram luxação traumática, Gazelius, Olgart e Edwall (1988), puderam constatar total restabelecimento da circulação sanguínea em quatro incisivos inferiores.

Neste aspecto, Olgart, Olgart e Edwall (1988), avaliando dentes que sofreram luxação, concluiu que o exame por meio do Laser Doppler é capaz de determinar a vitalidade pulpar em situações nas quais os achados clínicos convencionais mostram-se imprecisos.

Para mais, Ingolfsson et al. (1994), avaliaram a capacidade da fluxometria a laser em distinguir dentes portadores de polpas vitais e necróticas, verificando que as leituras de fluxometria nos dentes com polpas necróticas eram de menor valor do que naqueles com polpas vitais. Porém desde já havia uma preocupação com as 
características da sonda e, neste mesmo estudo, os autores concluíram que uma menor distância entre as fibras componentes da sonda tornavam-se mais sensível na distinção entre polpas vitais e necróticas.

Evans et al. (1999), compararam o fluxo sanguíneo entre dentes íntegros e aqueles submetidos à pulpectomia e puderam concluir que embora o Laser Doppler exija técnica apurada e consuma um tempo excessivo, mostrou grande eficiência no diagnóstico da vitalidade pulpar.

Em contrapartida, Ikawa et al. (1999), advertem sobre a interferência dos tecidos vizinhos ao elemento dental. Os autores analisaram a dispersão da luz quando da aplicação do Laser Doppler na verificação da vitalidade pulpar. Os resultados demonstraram que a luz emitida é dissipada em áreas vizinhas ao dente testado, levando a um diagnóstico impreciso.

Para mais, Odor et al. (1999), ao avaliarem a propagação da luz laser sobre a superfície dentária de alguns animais frequentemente utilizados em experimentos endodônticos, concluíram que aqueles que possuem dentes muito pequenos, como gatos e ratos, podem mostrar resultados imprecisos.

Goodies, Winthrop e Whitw (2000), avaliaram comparativamente o Laser Doppler e o teste elétrico para determinação da vitalidade pulpar. Os autores utilizaram 14 pré-molares superiores hígidos para análise e com o auxílio de um aparato pré-confeccionado para o estudo, promoveram o resfriamento da superfície dos dentes e acoplaram termopares na superfície com o intuído de verificar as mudanças de temperatura durante a aplicação dos testes. Cada dente recebeu o teste elétrico e mensuração do fluxo através da Fluxometria de Laser Doppler, antes e depois do início do resfriamento observando um maior grau de precisão do Laser em ambas as situações. 
Nogueira (2003) objetivou estabelecer parâmetros de utilização desta nova tecnologia, além de novos critérios para a análise de resultados. Os grupos experimentais de seu estudo foram compostos por 18 pacientes sendo os resultados analisados por meio do estabelecimento de variação percentual de fluxo entre dente vital e não-vital. O valor médio da variação de fluxo para os dentes vitais foi de $92,01 \%$ e para os dentes desvitalizados $35,52 \%$ o que mostrou diferenças significativas entre os resultados experimentais dos grupos avaliados. Os dados obtidos permitiram concluir que a Fluxometria Laser Doppler forneceu resultados confiáveis nas diferentes situações clínicas utilizadas, e que eficácia do método proposto foi constatada com o resultado de sensibilidade e especificidade iguais a 1 , traduzindo que o critério empregado conseguiu detectar corretamente todos os dentes desvitalizados e que além disso, não identificou nenhum dente saudável erroneamente.

Neste rumo, podemos relacionar outro teste fisiométrico denominado Espectrofotometria.

Segundo Nissan et al. (1992), a espectrofotometria por duplo comprimento de onda é um método para diagnóstico da vitalidade pulpar que busca mensurar as trocas de oxigenação sanguínea no leito capilar, não dependendo do pulso vascular do tecido examinado, detectando presença ou ausência de sangue oxigenado em comprimentos de onda de 760 a $850 \mathrm{~nm}$.

Os autores se propuseram a avaliar in vitro a capacidade da espectrofometria de identificar dentes cujas câmaras pulpares eram mantidas vazias, preenchidas com tecido pulpar fixado ou preenchidas com sangue oxigenado, concluindo que a espectrofotometria pode ser considerada um método eficaz para avaliação da condição pulpar. 
Ainda neste sentido, encontramos a Fotopletismografia. Trata-se de um método não invasivo para monitoração da circulação sanguínea intrapulpar.

Ikawa, Horiuchi e Ikawa (1994), estudaram o fluxo sanguíneo pulpar através da fotopletismografia, avaliando as propriedades da transmissão da luz de dentes humanos extraídos e a circulação sanguínea periférica em comprimentos de onda entre 400 e $800 \mathrm{~nm}$, verificando que a redução da transmissão da luz a comprimentos de onda menores que $600 \mathrm{~nm}$ pelo sangue oxigenado sugerem que a luz é absorvida pelo conteúdo sanguíneo.

Outro método que vem sendo estudado para o auxílio ao diagnóstico da vitalidade pulpar, através da análise de oxigenação sanguínea é a Oximetria de pulso.

A oximetria de pulso é um método não invasivo para determinação da saturação de oxigênio e taxa de pulso de um tecido; o princípio consiste em dois diodos emissores de luz, um vermelho e outro infravermelho, que são ligados em ciclos de 500 vezes por segundo. As emissões destas fontes de luz são captadas por um fotodiodo receptor e convertidas por circuitos eletrônicos em saturação arterial de oxigênio e taxas de pulso (KIDD; VICKERS, 1989; MILLS, 1992).

Schnettler e Wallace (1991) estudaram 49 incisivos centrais superiores humanos, os quais eram avaliados quanto á vitalidade pulpar por testes térmicos, elétrico e oximetria. Foram observadas leituras de taxa de pulso e saturação de oxigênio para os dentes vitais e nenhuma leitura para dentes tratados endodonticamente, confirmado a capacidade do oxímetro de pulso em diagnosticar o estado do processo patológico pulpar, bem como a verificação da vitalidade pulpar em dentes traumatizados. 
Mills (1992) ratifica as vantagens deste recurso para determinação da vitalidade pulpar através da monitoração do suprimento sanguíneo dental, porém cita algumas desvantagens com relação ao aparato tais como: movimentação do sensor e do aparelho, sinal fraco, necessidade de uma sonda dental especial e de um gel de união entre esta e o dente para melhor transmissão da luz.

Em 1996, Noblett et al., propuseram-se a desenvolver um sensor dental e avaliar o potencial e precisão da oximetria de pulso em odontologia, concluindo que o oxímetro de pulso pode ser adaptado para detecção da circulação sanguínea pulpar e, portanto diagnosticar a vitalidade da polpa; a presença de circulação sanguínea na câmara pulpar determinaria a vitalidade pulpar a despeito da ausência de resposta sensorial. A objetividade deste método de diagnóstico oferece vantagens sobre os demais métodos, os quais se baseiam na resposta nervosa sensorial que varia com a personalidade do paciente e experiência; a natureza não invasiva da oximetria de pulso pode também resultar em grande aceitação e cooperação por parte do paciente com os procedimentos de diagnóstico.

Kahan et al. (1996), desenharam ,construíram e testaram uma sonda para dentes usando um oxímetro Biox 3740; determinaram as ondas de pulso de dentes anteriores superiores e inferiores, tomando como controle as leituras obtidas dos dedos dos indivíduos parecendo que estas eram equivalentes, porém não constantemente, havendo uma diferença significante entre as porcentagens de sincronização de pulso nos incisivos superiores e inferiores.

A capacidade de determinação da vitalidade pulpar pela oximetria de pulso também foi salientada por Radhakrishnan, Munshi e Hedge em 2002, que avaliou os incisivos centrais e laterais de 100 crianças com o teste elétrico e a oximetria de pulso concluindo que quando comparado ao teste elétrico e, desde que 
se obtenha níveis aceitáveis de saturação arterial de oxigênio, tal recurso pode ser de extrema importância, principalmente em crianças onde a cooperação para realização dos testes e a incompleta inervação sensorial pulpar, reduzem a efetividade do teste elétrico.

Calil (2003) realizou um estudo em 17 pacientes de ambos os sexos, com idade entre 26 e 38 anos, dos quais selecionou 28 incisivos centrais superiores e 32 caninos superiores. As mensurações foram realizadas através do aparelho modelo Oxigraph da empresa System Partner, no qual foi acoplado um sensor para uso odontológico. Nesse estudo, houve uma correlação entre o nível de oxigenação sanguínea obtido do dedo indicador do paciente e o dos dentes testados.

Abrão (2006), utilizando o mesmo modelo de oxímetro, avaliou 26 pacientes de ambos os sexos, com idade entre 8 e 53 anos, dos quais foram selecionados 59 dentes permanentes acometidos por diferentes traumatismos com respostas sensitivas negativas ao gás refrigerante e ausência de um segundo sinal ou sintoma que nos levasse a suspeitar de mortificação pulpar. Este estudo demonstrou que a oximetria de pulso é um teste objetivo onde conseguimos avaliar as reais condições de vitalidade pulpar valendo-se da determinação do fluxo e oxigenação do tecido pulpar, validando o teste como recurso auxiliar no diagnostico de dentes traumatizados. Contudo, é necessário, melhorar as características técnicas de aplicabilidade do teste.

Em recente estudo, Gopikrishna, Tinagupta e Kandaswamy (2007) analisaram comparativamente utilização de oximetria de pulso, teste elétrico e teste térmico feito com gás tetrafluoretano na determinação da vitalidade pulpar em 80 dentes unirradiculares. Os autores obtiveram resultados confiáveis em $86 \%$ dos dentes no teste térmico, $81 \%$ dos dentes no teste elétrico e $97.5 \%$ na oximetria de pulso. 
Concluindo nessa situação que a oximetria de pulso é um teste eficiente e seguro na determinação da vitalidade pulpar em dentes unirradiculares.

Os mesmos autores, na seqüência estudaram a utilização da oximetria de pulso para determinação da vitalidade pulpar em dentes que haviam sofrido trauma recente. Na comparação com os testes térmicos e elétricos, obtiveram resposta imediata da condição pulpar do elemento traumatizado quando da utilização da oximetria, resposta que se manteve constante durante os 6 meses do experimento. Os testes térmicos e elétricos obtiveram respostas em $29,4 \%$ dos dentes no $28^{\circ}$ dia progredindo gradualmente e atingindo $94,11 \%$ dos dentes em 3 meses. A parestesia temporária das fibras nervosas sensoriais afeta diretamente a resposta aos testes elétricos e térmicos, o que não ocorre quando utilizamos a oximetria de pulso. Dessa forma, os autores puderam concluir que se trata de um método eficaz para determinação da vitalidade pulpar em casos de trauma.

Caldeira et al. (2007) utilizando-se também da oximetria de pulso avaliou in vivo a vitalidade pulpar de 30 dentes traumatizados. Os resultados mostraram diferenças de saturação de oxigênio $\left(\mathrm{SaO}_{2}\right)$ entre traumas de tecido duro $(87,5 \%)$ ou de suporte $(88,5 \%)$ e entre aqueles que respondem $(90,53 \%)$ ou não $(86,66 \%)$ ao teste térmico, levando a considerar que a oximetria de pulso é um método viável de determinação da vitalidade pulpar, mesmo diante de algumas dificuldades na captação dos sinais e obtenção dos dados. 


\subsection{Avaliação diagnóstica através da mensuração da temperatura}

Levando-se em consideração o que ocorre após reimplantes dentários, concussões, luxações e cirurgias ortognáticas e conhecendo as limitações encontradas nos testes supracitados, será extremamente valioso ter um método que verifique a vitalidade pulpar baseando-se em fluxo sanguíneo ao invés de suprimento nervoso.

Howell, Duell e Mullaney (1970), na busca por métodos mais eficazes na determinação da vitalidade pulpar, propôs a mensuração da temperatura da superfície dentária. Partindo do princípio que a polpa de um dente se torna não-vital quando ocorre diminuição e posterior perda do suprimento sanguíneo interno, levando a uma queda de temperatura na superfície do dente. Com o uso de cristal líquido o autor obteve temperaturas inferiores nos dentes não vitais em relação aos vitais, sugerindo que a microcirculação existente nos tecidos adjacentes não alteram significantemente a temperatura de um dente com polpa necrosada.

Neste rumo, podemos a inferir que a temperatura da superfície dentária fornece dados sobre a vitalidade pulpar. Desde então, novas técnicas surgiram com o intuito de determinar a vitalidade pulpar de um dente através da mensuração da temperatura da superfície de sua coroa.

O uso de termistores tem sido descrito com freqüência na literatura. Trata-se de um dispositivo que funciona através de efeitos termoelétricos que surgem quando dois fios metálicos diferentes são unidos. Segundo Nicholas e White (1994) esta técnica mostra ter $0,5 \%$ de precisão. Uma grande limitação da técnica é o fato dos 
termistores registrarem a temperatura apenas no local onde existe contato com a superfície dentária, impedindo análises de áreas extensas.

Em 1986a, com a utilização de termistores, Fanibunda demonstrou que não há diferença na temperatura da superfície de dentes vitais e não-vitais apesar da expectativa de que um suprimento sanguíneo pulpar normal poderia ter elevado a temperatura. Concluiu-se que o efeito do suprimento sanguíneo pulpar foi mascarado pela troca de aquecimento entre os dentes, o meio e os tecidos de suporte (FANIBUNDA, 1985).

Contudo, Fanibunda (1986a, b), utilizando um termômetro digital sugeriu que poderia ser possível relatar o suprimento sanguíneo pulpar pela taxa de retorno da temperatura da superfície do dente à temperatura normal após a aplicação um de estímulo térmico (calor ou frio). Como um estímulo frio, o autor umidificou os dentes com saliva e mediu a temperatura enquanto o dente era subseqüentemente exposto pela abertura da boca. O posterior aquecimento da superfície por evaporação causou uma queda na temperatura. A temperatura caiu bruscamente e vagarosamente recuperou uma temperatura de equilíbrio. Supôs-se que o tempo levado para atingir o equilíbrio dependia do suprimento sanguíneo pulpar.

Smith et al. (2004) avaliaram as mudanças de temperatura ocorridas na superfície de coroas após o recebimento de estímulo térmico. Os autores utilizaramse de mini-termômetros em contato com a coroa e não obtiveram resultados que pudessem relacionar a temperatura registrada com vitalidade pulpar, descartando o método como teste de vitalidade.

A utilização da termografia infravermelha em odontologia, iniciou-se com o estudo de Crandrell e Hill (1966) na diagnose de abscessos periapicais. Desde 
então essa nova tecnologia vem ganhando espaço em pesquisas em outras áreas da odontologia.

Pogrel, Yen e Taylor (1989) justificaram as descobertas de Fanibunda (1986b) que, após o resfriamento, os dentes vitais poderiam reaquecer mais rapidamente do que os dentes não-vitais. Com a utilização da imagem infravermelha, eles também notaram um efeito perturbador das correntes de ar na boca, e defenderam o isolamento dos dentes por lençóis de borracha para excluir tal efeito.

Em recente estudo, na área da dentística, Hussey, Biagioni e Lamey (1995), avaliaram a reação exotérmica provocada pela polimerização de resina composta para restaurações em 10 incisivos superiores que necessitavam de tratamento restaurador e respondiam positivamente aos testes de sensibilidade pulpar. Para tal, utilizaram-se da termografia infravermelha e constataram que a exotermia é praticamente instantânea a partir do momento de ativação da luz de fotopolimerização podendo atingir picos de $12^{\circ} \mathrm{C}$, sugerindo que o tecido pulpar pode vir a ser comprometido durante a polimerização da resina. Os autores concluíram que a termografia infravermelha constitui um método eficaz na quantificação das mudanças de temperatura durante a polimerização de resinas in vivo.

A termografia infravermelha tem sido usada também na Endodontia como metodologia avançada para estudos in vitro.

Hussey et al. (1997) avaliou o aumento de temperatura na superfície das raízes de pré-molares durante o preparo de condutos para recebimento de núcleos intra-radiculares in vitro. Os autores obtiveram índices de elevação de temperatura de até $80^{\circ} \mathrm{C}$, contrariando estudos preliminares que utilizavam termistores para esta verificação. Dessa forma podemos inferir sobre a superioridade da metodologia 
aplicada para verificação de temperatura. Os autores sugerem o uso de irrigação nos motores para minimizar danos ao periodonto.

Mc Cullagh et al. (2000), compararam o uso de termistores com a utilização da termografia infravermelha na análise da elevação da temperatura nos canais radiculares durante a técnica de obturação termoplastificada. Concluíram que a termografia constitui um método eficaz para a análise de mudanças de padrões de temperatura e localização de pontos onde encontramos picos de temperatura na face do elemento dental, suprindo as limitações encontradas nos termistores.

Lipski (2006) avaliou a elevação da temperatura ocasionada por sistemas de obturação termoplastificada em 15 raízes de dentes naturais unirradiculares e 15 raízes de dentes naturais unirradiculares inferiores. O autor utilizou o sistema de obturação Obtura II, que utiliza guta-percha aquecida a $160^{\circ} \mathrm{C}$. Os dentes superiores tiveram aumento de temperatura menor quando comparados aos inferiores, justificado pela menor espessura de dentina presente nos dentes unirradiculares inferiores. A metodologia sugere que se extrapolarmos esse estudo para a prática clínica não teremos quaisquer danos à ligamentos periodontais, no entanto o autor sugere cautela quando da utilização do sistema de obturação em dentes inferiores.

Ribeiro et al. (2007) avaliou in vitro os efeitos térmicos da irradiação de Laser Diodo $(810 \mathrm{~nm})$ em raízes de 24 incisivos inferiores. As temperaturas obtidas não ultrapassaram o limite de segurança para danos periodontais, no entanto os autores sugerem que após cada irradiação seja feito um período de 20 segundos de descanso a fim de evitar um aumento excessivo de temperatura nos tecidos quando da nova irradiação, seja ela no modo contínuo ou pulsátil.

Dessa forma podemos concluir que a termografia infravermelha mostra-se um método eficaz na análise do aumento de temperatura em superfície dentinária nos 
trabalhos in vitro. Portanto, cabe agora aprimorar a técnica e verificar sua real eficácia em estudos in vivo.

Kells et al., em 2000a, b, desenvolveram um protocolo para a utilização da termografia infravermelha em endodontia. Os autores avaliaram a temperatura da face vestibular de um total de 12 incisivos laterais superiores hígidos de 6 pacientes sob isolamento absoluto e ambiente climatizado. As imagens foram obtidas a cada 30 segundos durante um período de 20 minutos, em seqüências com o aparelho de ar condicionado ligado e desligado, focando uma área do terço cervical e outra do terço incisal da face vestibular dos dentes. Concluíram não haver diferença significante de temperatura nos dois terços analisados e que o período de 15 minutos sob isolamento absoluto é adequado para estabilizar a temperatura da superfície dentária.

Os autores investigaram ainda, o padrão de reaquecimento de dentes clinicamente saudáveis após estimulação com frio, utilizando bastões de gelo e jato de ar da seringa tríplice acoplada ao equipamento odontológico. Concluíram que 3 minutos são suficientes para a tomada da temperatura.

Dos trabalhos apresentados na Endodontia, caracteriza-se o aspecto experimental em que em cada um procuram-se diferentes métodos de mensuração da temperatura com o intuito de melhorar a eficácia na determinação da vitalidade pulpar.

Existe, entretanto, um consenso de que essa inovação tecnológica é capaz de ser útil no diagnóstico da vitalidade pulpar, mas não há critérios objetivos para o emprego e obtenção de resultados confiáveis. Portanto, definir protocolos e critérios que possam avaliar resultados das aplicações, torna-se objetivo fundamental. 


\section{PROPOSIÇÃO}

O objetivo deste estudo foi avaliar a aplicabilidade do uso da imagem infravermelha em dentes portadores de polpa vital e em dentes tratados endodonticamente, com ou sem o emprego de isolamento absoluto, estabelecendo parâmetros para sua utilização como teste de vitalidade pulpar. 


\section{MATERIAL E MÉTODOS}

Esse estudo foi realizado com aprovação do Comitê de Ética em Pesquisa da FOUSP (Anexo A). A seleção dos casos iniciou-se com a tomada dos dados pessoais referentes a cada paciente, em ficha apropriada, destinada para esse estudo (Apêndice A). Os pacientes selecionados assinaram o Termo de Consentimento Livre e Esclarecido (Apêndice B).

\subsection{Critérios de inclusão}

Foram selecionados quatro pacientes de ambos os sexos, com idades entre 20 e 40 anos, dos quais selecionamos seis dentes anteriores que preencheram os seguintes requisitos:

$\checkmark$ portadores de polpa vital, clinicamente sem alteração inflamatória $(n=4)$;

$\checkmark$ tratados endodonticamente sem sinais ou sintomas clínico-radiográfico $(n=2)$;

$\checkmark$ coroas íntegras ou com restaurações de diâmetro não maiores que $2 \mathrm{~mm}$, localizadas em regiões distantes daquelas onde seriam aplicados os testes de vitalidade;

$\checkmark$ ao exame radiográfico, sem processos degenerativos ou reabsortivos na câmara pulpar ou canal radicular, sem rompimento da lâmina dura, espaço do 
espaço pericementário dentro dos parâmetros de normalidade, sem alterações periapicais como rarefação ou condensação óssea.

\subsection{Critérios de exclusão}

Foram excluídos da amostra os dentes que apresentaram:

$\checkmark$ qualquer relato de sintomatologia dolorosa, denotando algum tipo de alteração pulpar inflamatória;

$\checkmark$ história de traumatismo dentário;

$\checkmark$ processos cariosos;

$\checkmark$ com alteração cromática da coroa dentária;

$\checkmark$ alterações periodontais como presença de bolsa profunda;

$\checkmark$ edema;

$\checkmark$ mobilidade não fisiológica;

$\checkmark$ sensibilidade dolorosa à palpação apical e à percussão vertical ou horizontal.

Todos os pacientes foram submetidos a testes de sensibilidade pulpar sob isolamento relativo com roletes de algodão e sucção de saliva com sugadores plásticos descartáveis acoplados em bomba a vácuo e posterior secagem dos dentes com gaze hidrófila.

Quando da aplicação do estímulo térmico, os pacientes receberam a orientação de levantar o antebraço e mão esquerdos, imediatamente após perceberem sensibilidade, mantendo-os levantados enquanto persistir a 
sintomatologia e abaixar lentamente conforme a diminuição. O tempo de resposta ou sua ausência foram anotados na ficha do paciente.

O exame radiográfico foi realizado pela técnica de paralelismo com filme periapical e observação com lupa 10x com auxílio de negatoscópio.

\subsection{Procedimento clínico}

Foi realizado o isolamento absoluto nos dentes em questão, tomando-se o cuidado de recobrir o nariz do paciente com o lençol de borracha de tamanho 13,5cm x 13,5cm. (Madeitex ${ }^{\circledR}$ São José dos Campos, São Paulo, Brasil) a fim de eliminar correntes de ar provenientes da respiração.

Os pacientes foram orientados a não comer, beber ou fumar nos 60 minutos antecedentes ao procedimento, para que não houvesse um aumento da temperatura da cavidade oral devido ao calor da fumaça provocada pelo cigarro.

Após o isolamento absoluto, o paciente permaneceu sentado por 20 minutos para a estabilização de sua temperatura corpórea. O termostato do ambiente permaneceu na marca de $20^{\circ} \mathrm{C}$ durante todo o experimento.

A obtenção da imagem digital termográfica infravermelha foi realizada através do termovisor modelo ThermaCAM SC 3000 (FLIR Thermal Infrared Camera Systems, USA) com lente de distância focal de $10 \mathrm{~cm}$ (Figura 4.1). 


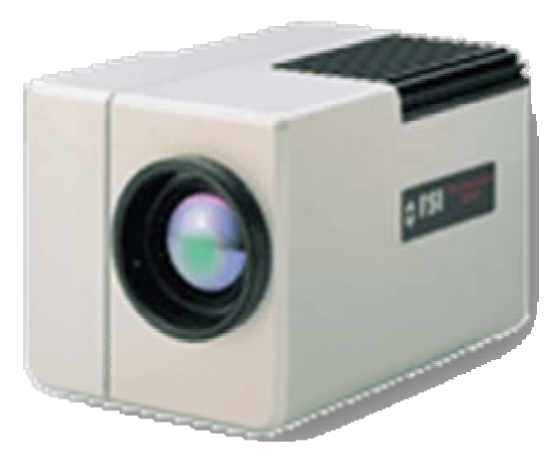

Figura 4.1 - Termovisor ThermaCAM SC 3000

Os pacientes tiveram a cabeça e queixos apoiados em um suporte de base fixa desenvolvido particularmente para este estudo, onde era possível obter o máximo paralelismo entre o termovisor e os dentes em questão, além de facilitar o ajuste de foco do aparelho.

Durante todo o procedimento os operadores permaneceram nas mesmas posições para que não houvesse alterações de temperatura próxima ao local da tomada.

Foram realizadas 4 tomadas para cada paciente. A primeira foi chamada de linha base, onde era realizada a tomada no dente isolado com o paciente em posição por 60 segundos sem nenhum estímulo.

Após esse período, e com o paciente na mesma posição, foi realizada uma segunda tomada, desta vez, com aplicação através de uma haste flexível de algodão (Cotonete $^{\circledR}$ - Johnson \& Johnson. São José dos Campos, São Paulo - Brasil) com gás refrigerante (Endofrost ${ }^{\circledR}$ - Wilcos do Brasil, Rio de Janeiro, Rio de Janeiro Brasil) por 2 segundos no terço médio para cervical da face vestibular do dente em questão (Figura 4.2). 


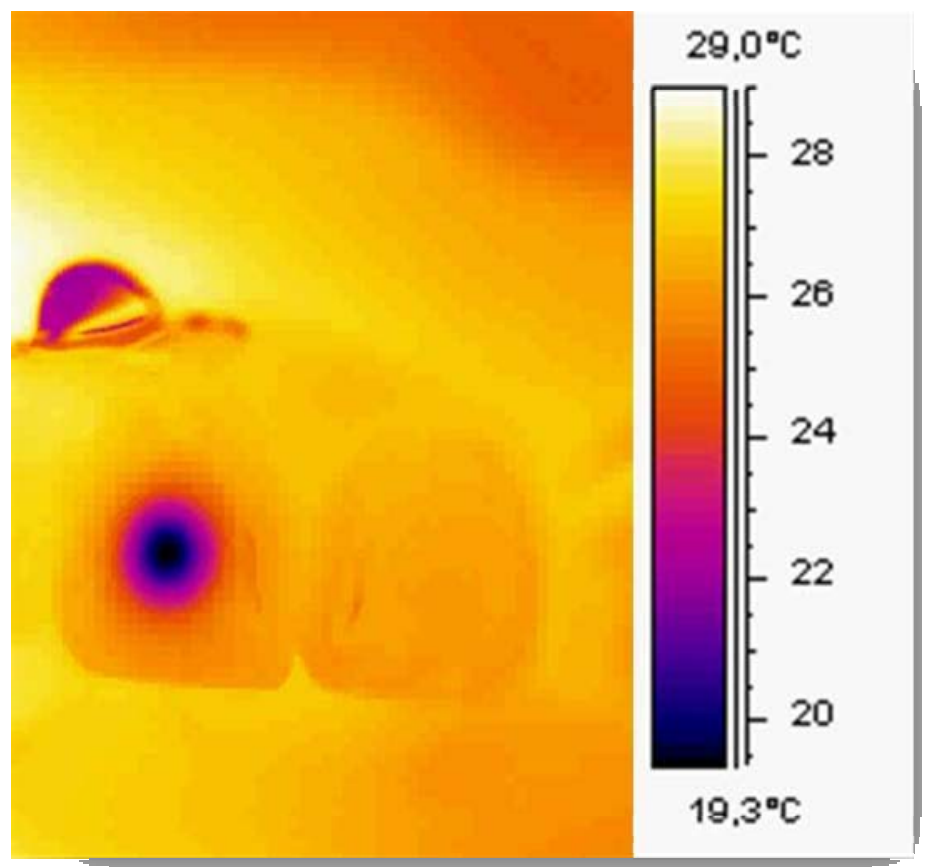

Figura 4.2 - Imagem termográfica do dente 11 portador de polpa vital logo após a aplicação do estímulo térmico, com a utilização do isolamento absoluto

Ao final da tomada, o isolamento absoluto era retirado e outras duas tomadas foram realizadas: uma com a utilização de um abridor de boca convencional (Fabinject $^{\circledR}$, Pindamonhangaba, São Paulo, Brasil) utilizado para fotografia odontológica e com os dentes em oclusão e aplicação de estímulo térmico da mesma forma anterior (Figura 4.3). A outra tomada era realizada na seqüência e sem o estímulo térmico (linha base). 

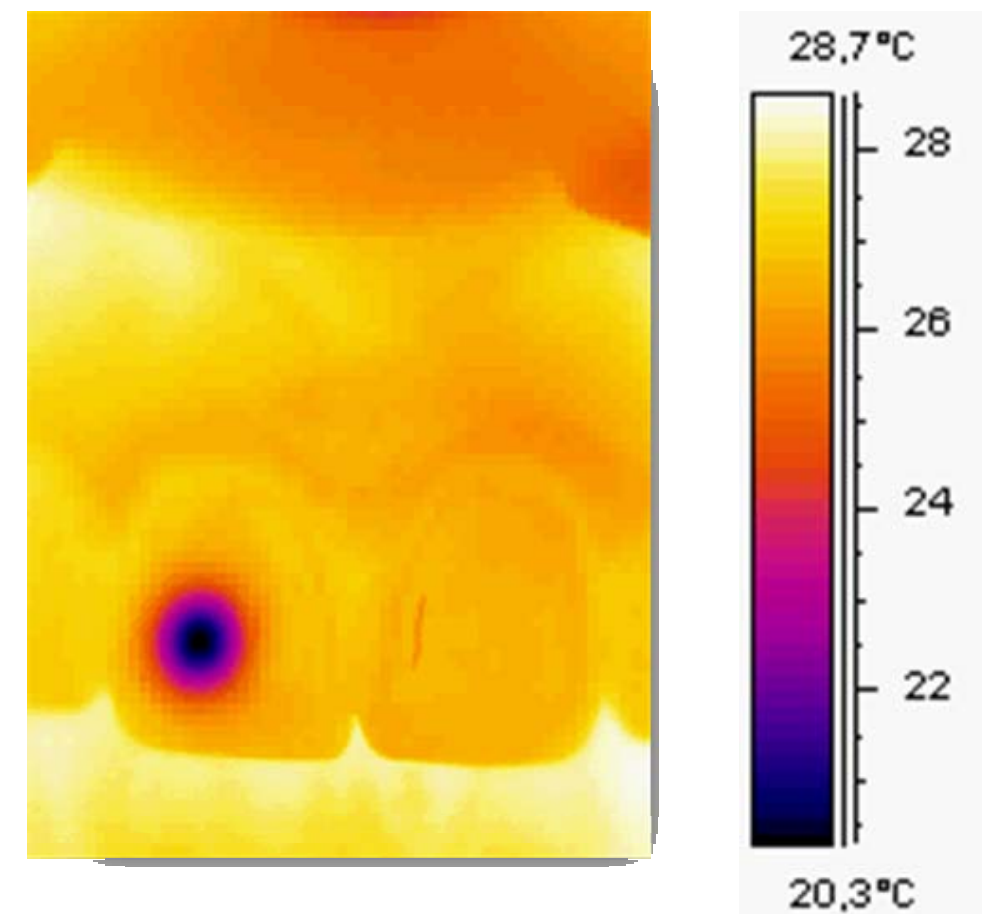

Figura 4.3 - Imagem termográfica do dente 11 portador de polpa vital logo após a aplicação do estímulo térmico, sem a utilização do isolamento absoluto

Todas as tomadas termográficas foram registradas em vídeo, em extensão .avi para melhor análise dos dados.

No programa ThermaCAM Researcher foi identificada inicialmente a temperatura mínima obtida de cada tomada através da delimitação da área de estímulo nos dentes avaliados, para que pudesse servir de referência para a análise da temperatura antes da aplicação do gás refrigerante e, após sua retirada, o retorno à temperatura considerada inicial.

Os dados foram anotados e tabulados no programa OriginPro versão 8.0. 


\section{RESULTADOS}

Os resultados obtidos mostram não haver diferença na temperatura da superfície dentária de dentes portadores de polpa vital e dentes tratados endodonticamente.

A temperatura ambiente variou em apenas $0,16^{\circ} \mathrm{C}$, o que permite afirmar que não houve interferência de temperatura externa ao dente.

Em relação à variação de temperatura produzida pelo gás refrigerante $\left(\right.$ Endofrost $\left.^{\circledR}\right)$ durante dois segundos no terço médio da face vestibular de cada dente, a temperatura mínima atingida em dentes portadores de polpa vital e dentes tratados endodonticamente também não mostrou diferença significante (Gráfico 5.1 e Apêndice C).

Os períodos de tempo que antecedem a aplicação do estímulo térmico estão expressos em valores negativos, onde zero é o momento da aplicação.

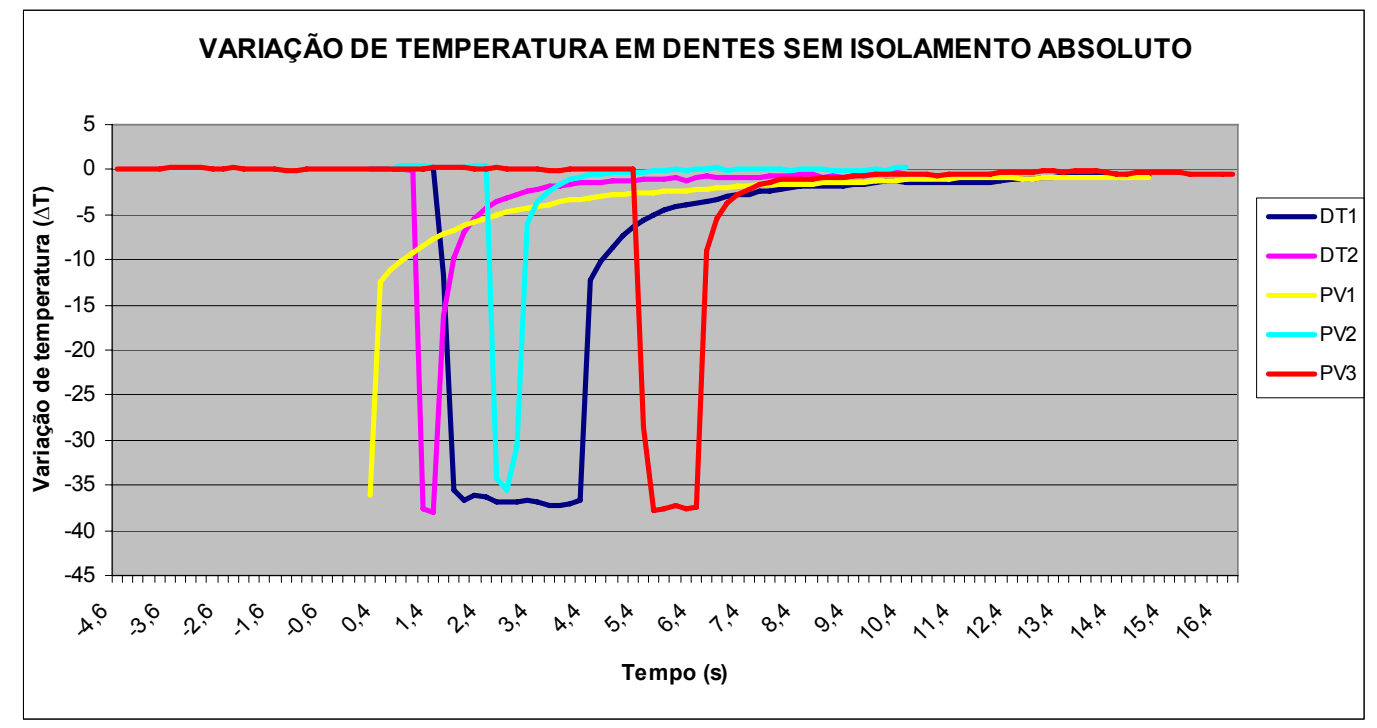

Gráfico 5.1 - Variação de temperatura de todos os dentes analisados sem a utilização de isolamento absoluto quando da aplicação do gás refrigerante DT - dente tratado endodonticamente; PV - dente portador de polpa vital; 1,2,3,4 - sequência de dentes que foram avaliados 
Quanto ao uso do isolamento absoluto, os resultados sugerem que dentes isolados com lençol de borracha demoram mais tempo para atingir a temperatura mínima provocada pelo teste térmico. No entanto, as médias das temperaturas mínimas atingidas não diferem entre os grupos estudados (Gráfico 5.2 e Apêndice D).

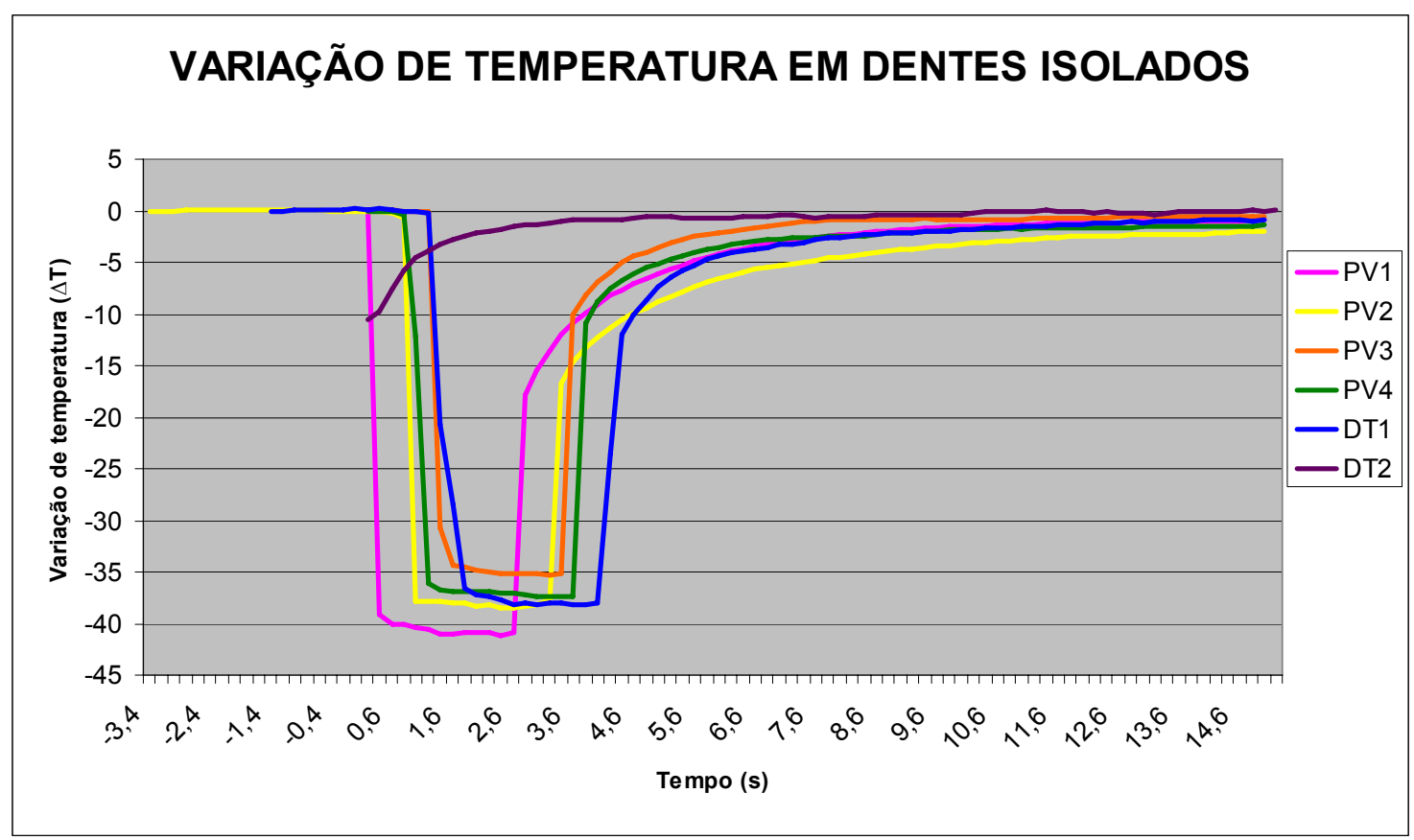

Gráfico 5.2 - Variação de temperatura de todos os dentes analisados com a utilização de isolamento absoluto quando da aplicação do gás refrigerante DT - dente tratado endodonticamente; PV - dente portador de polpa vital; 1,2,3,4 - sequência de dentes que foram avaliados

No que tange a taxa de retorno do fluxo e recuperação da temperatura inicial, dentes isolados demoram mais tempo para retornar as temperaturas iniciais. 


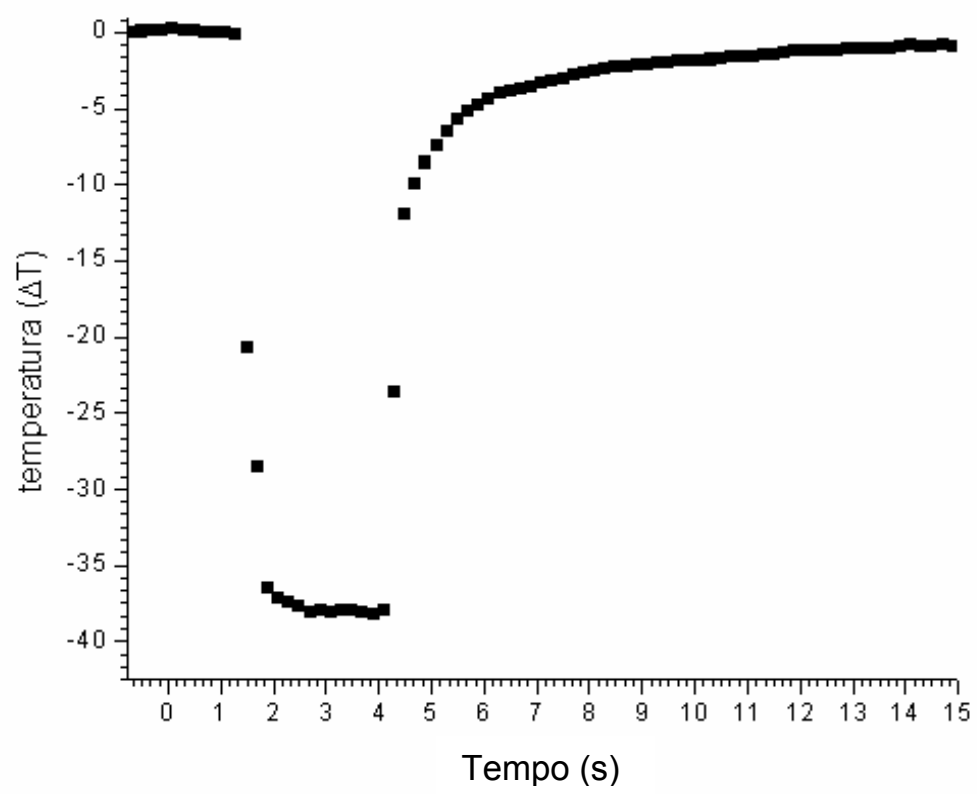

Gráfico 5.3 - Relação tempo/temperatura $(\Delta \mathrm{T})$ com a utilização de isolamento absoluto em um incisivo lateral tratado endodonticamente

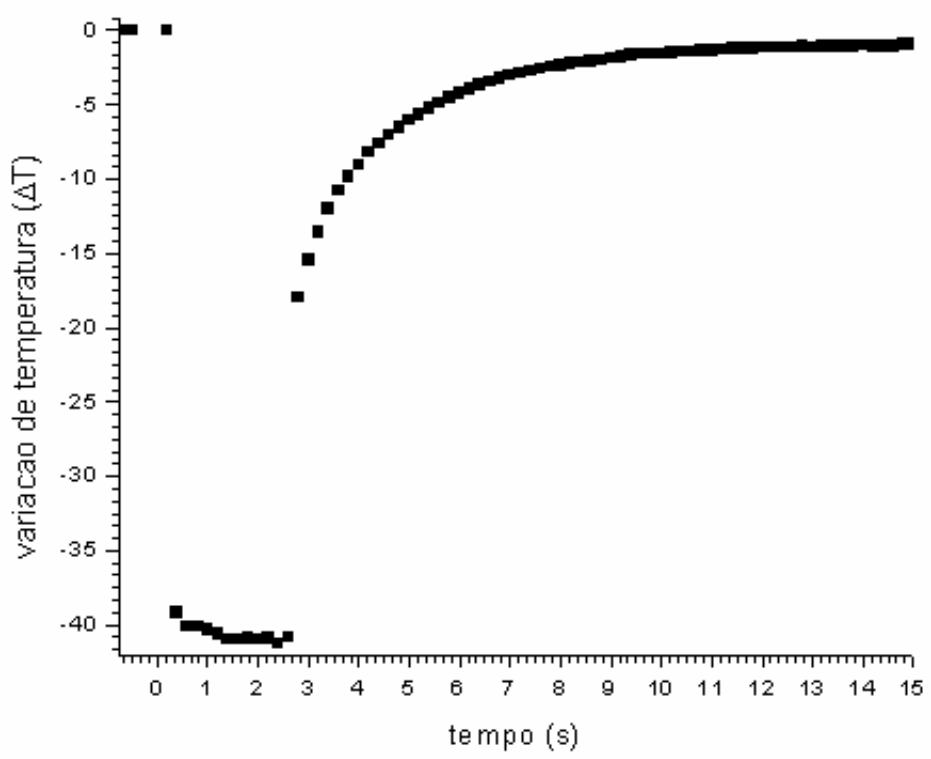

Gráfico 5.4 - Relação tempo/temperatura $(\Delta \mathrm{T})$ com a utilização de isolamento absoluto em um incisivo lateral com vitalidade pulpar 


\section{DISCUSSÃO}

A verificação da vitalidade pulpar estabelece certos conceitos muito particulares, necessários à sua interpretação, essencialmente no que se refere ao conhecimento dos aspectos de normalidade e das modificações que ocorrem na estrutura dentária e no complexo pulpar. As respostas obtidas quando da aplicação dos testes de vitalidade pulpar fornecem dados importantes para a determinação da condição fisiológica do complexo dentino-pulpar.

O diagnóstico da vitalidade pulpar através de meios que mensuram a temperatura parece superar todas as desvantagens inerentes aos testes térmicos e elétricos, como a necessidade da estimulação, subjetividade da resposta sensorial, as variáveis decorrentes da espessura de dentina-esmalte dos dentes, a idade do paciente, a condição da estrutura dentária, entre outras.

Na busca por métodos mais eficazes na determinação da vitalidade pulpar, foi proposta a mensuração da temperatura da superfície da coroa dentária. Parte-se do princípio que a polpa de um dente se torna não-vital quando ocorre diminuição e posterior perda do suprimento sanguíneo interno, levando a uma queda de temperatura na superfície do dente.

Tal fato tem sido analisado desde os anos 70 , quando os autores Howell, Duell e Mullaney (1970), com o uso de cristal líquido, obtiveram temperaturas inferiores nos dentes não vitais em relação aos vitais, sugerindo ainda que a microcirculação existente nos tecidos adjacentes não alteram significantemente a temperatura de um dente com polpa necrosada. 
Em 1986, com a utilização de termistores, Fanibunda (1986a) demonstrou que não há diferença na temperatura da superfície de dentes vitais e não-vitais, apesar da expectativa de que um suprimento sanguíneo pulpar normal poderia elevar a temperatura. $\mathrm{O}$ autor sugeriu que o efeito do suprimento sanguíneo pulpar foi mascarado pela troca de aquecimento entre os dentes, o meio e os tecidos de suporte.

Por outro lado, Kells et al. (2000a), utilizando-se da termografia infravermelha mostraram que não existe diferença significante entre os terços cervical e incisal da superfície externa da coroa de incisivos vitais, o que contraria a hipótese de que áreas mais próximas a um tecido vascularizado (no caso, o tecido periodontal) pudesse apresentar maior temperatura.

Contudo, Fanibunda (1986a, b), utilizando um termômetro digital, sugeriu que poderia ser possível relatar o suprimento sanguíneo pulpar pela taxa de retorno da temperatura da superfície do dente à temperatura normal após a aplicação um de estímulo térmico (calor ou frio). Nesse estudo, a temperatura caiu bruscamente e vagarosamente recuperou uma temperatura de equilíbrio. Supôs-se que o tempo levado para atingir o equilíbrio dependia do suprimento sanguíneo pulpar.

Em 2004, Smith et al. avaliaram as mudanças de temperatura ocorridas na superfície de coroas após o recebimento de estímulo térmico. Os autores utilizaramse de mini-termômetros em contato com a coroa, mas não obtiveram resultados que pudessem relacionar a temperatura registrada com vitalidade pulpar, descartando 0 método como teste de vitalidade.

A termografia infravermelha é um método não invasivo que avalia a distribuição de temperatura num corpo através da radiação emitida pela sua superfície e a transforma numa representação gráfica da temperatura superficial. 
Trata-se de um recurso de alta tecnologia que permite observar a temperatura exata da área a ser estudada.

Sabe-se que a temperatura corpórea gira em torno de $37^{\circ} \mathrm{C} . \mathrm{O}$ tecido cutâneo é geralmente $5^{\circ} \mathrm{C}$ mais frio pois perde calor constantemente para o ambiente por evaporação, convecção, condução e radiação. A variação da temperatura da pele é resultante da mudança na perfusão tecidual local e fluxo sangüíneo nas veias superficiais. O sangue venoso, proveniente de áreas metabolicamente mais ativas é normalmente mais quente que o sangue proveniente da drenagem de um tecido normal.

Como o calor é um dos sinais cardinais da inflamação, a termografia é capaz de acusar variação de temperatura a partir de $0.2{ }^{\circ} \mathrm{C}$, ou seja, até quando não se percebe ao exame de palpação da região, e até mesmo antes que seja notada sintomatologia dolorosa. A termografia acusa hot spots, ou seja, áreas com aumento de temperatura e cold spots, áreas com diminuição de temperatura, que também significam problema ${ }^{4}$.

Isto posto, espera-se poder constatar através da termografia infravermelha que um dente de polpa vital tenha temperatura da superfície coronária mais elevada em relação a um dente que tenha necrose pulpar ou tratamento endodôntico.

Em 2000a, Kells et al. sugeriram um protocolo para a utilização da termografia infravermelha para a determinação da vitalidade pulpar. Os autores analisaram a temperatura da face vestibular de dentes incisivos, delimitaram 2 áreas em cada dente, sendo a primeira do terço cervical até o terço médio da coroa e a segunda do terço médio da coroa até o terço incisal e não notaram diferença significante entre as áreas analisadas. No entanto, o protocolo proposto estabelece certos padrões,

\footnotetext{
${ }^{4}$ http://www.cavalocriouloonline.hpg.ig.com.br/fisioterapia.html
} 
como utilização de isolamento absoluto e climatização prévia do ambiente que inviabilizam o método no cotidiano da clínica odontológica.

Uma das situações a serem analisadas está na tentativa de se utilizar métodos que impeçam a interferência de estímulos externos sobre a área a ser testada com termografia, como, por exemplo, da própria respiração do paciente.

Baseado em estudos preliminares que sugerem a utilização de isolamento absoluto com lençol de borracha com o intuito de eliminar as correntes de ar provenientes da respiração (KELLS et al., 2000a; POGREL et al., 1989), a metodologia utilizada neste estudo avaliou essa limitação do recurso fazendo tomadas com isolamento absoluto e sem o uso do isolamento.

Para a avaliação termográfica utilizou-se neste estudo o sistema ThermaCAM SC3000 (Flir Systems), que foi projetado para atender aos exigentes requisitos de análise térmica em aplicações científicas, localização de alvos e ensaios não destrutivos.

O equipamento oferece sensibilidade térmica superior, ampla faixa dinâmica, alto desempenho na captação de imagens em ondas longas (8 a $9 \mu \mathrm{m}$ ) e capacidades de aquisição de dados em alta velocidade. A câmera infravermelha usada nesse experimento (ThermaCAM SC3000 - Figura 4.3.1) utiliza um sensor avançado FPA (que possui grande número de sensores que captam todos os pontos da imagem) do tipo Quantum Well Infrared Photodetector que fornece sensibilidade extremamente alta, a $30^{\circ} \mathrm{C}$, ideal para aplicações que requerem medições ultra precisas.

Outro detalhe a ser observado é que o equipamento utilizado no método de análise através de imagens infravermelhas é extremamente sensível e requer uma 
climatização prévia do ambiente para que não haja perda ou ganho de calor para o ambiente e uma possível interferência na temperatura do objeto a ser analisado.

De acordo com as recomendações técnicas, para este estudo a temperatura foi mantida estável $\left( \pm 20^{\circ} \mathrm{C}\right)$ durante todo o experimento e correntes de ar foram evitadas. Para tal, os operadores mantiveram-se nas mesmas posições do início ao término do experimento para que não houvesse sensibilização da câmera.

Além disso, o objeto a ser estudado necessita estar imóvel para que se consiga focalizar a imagem e então iniciar a tomada. Essa característica compõe uma das grandes dificuldades clínicas, principalmente quando se avaliam métodos de determinação da vitalidade pulpar através de estimulação térmica da polpa onde é quase instantânea a movimentação da cabeça do paciente em resposta à dor.

O posicionamento do paciente deve ser de total paralelismo com a câmera para que se obtenha foco no objeto a ser analisado.

Considerando que a posição de tratamento odontológico mantém o paciente deitado e nesta posição ocorre um aumento da circulação sanguínea na cabeça do paciente e possível aumento da temperatura no local, optou-se por manter os pacientes sentados à aproximadamente $10 \mathrm{~cm}$ da câmera (distância focal exigida pela lente da câmera).

Para efeito de padronização das imagens deste estudo, os pacientes mantiveram a cabeça e o queixo apoiados em um suporte de base fixa, desenvolvido particularmente para o experimento, o que permitiu obter o máximo paralelismo entre o termovisor e os dentes em questão.

O estudo foi realizado respeitando as necessidades do método e os resultados obtidos demonstraram que não houve interferências de correntes de ar no local do experimento, uma vez que a temperatura externa variou apenas $0,16{ }^{\circ} \mathrm{C}$, 
segundo os dados das tomadas de linha base. As tomadas de linha base foram realizadas no dente isolado com o paciente em posição por 60 segundos sem nenhum estímulo para que fosse possível relacionar as mudanças de temperatura provocadas pelo estímulo com a temperatura inicial do paciente em repouso. $\mathrm{O}$ mesmo foi feito sem o isolamento.

Independente do uso do isolamento absoluto não foi notada diferença significativa de temperatura entre os dentes portadores de polpa vital e aqueles com tratamento endodôntico (Gráfico $5.1 ; 5.2$ ). Esta situação pode ser justificada pelo fato da polpa estar enclausurada em um tecido altamente mineralizado e a câmera analisar somente a temperatura da superfície externa do dente.

Segundo Paiva e Antoniazzi (1988), a polpa é um tecido conjuntivo altamente vascularizado que, com o desenvolvimento do elemento dental, fica contido numa cavidade de paredes rígidas e inexpansíveis.

A distância da tomada termográfica até o conteúdo pulpar (composto de fibras colágenas, elementos celulares, fibras nervosas e vasos sanguíneos) pode ser um fator impedidor das variações de temperatura que poderiam ocorrer em casos de lesões inflamatórias ou necrose pulpar.

Dessa forma, cabe concentrar esforços no estudo da distribuição da temperatura no dente e os meios de condução do estímulo térmico através do esmalte e dentina, pois, possivelmente, há uma dissipação da temperatura pela superfície do esmalte além daquela que ocorre em profundidade através da dentina, que pode ocorrer em maior ou menor intensidade.

Como foi verificado, optou-se por escolher um teste térmico para que se pudesse avaliar a intensidade do resfriamento, retorno à temperatura inicial e comparar sua ação em dentes vitais e em dentes tratados endodonticamente. 
A escolha do teste térmico com gás refrigerante para esta análise teve como princípio o fato da ocorrência de resposta frente aos estímulos térmicos, decorrer das variações ocorridas na pressão interna intra-pulpar, quando da sensibilização do dente, segundo Beveridge e Brown (1965), e particularmente, quando das alterações de pressão intra-pulpar causadas pela mudança da temperatura em seu interior (VAN HASSEL; BROWN, 1969), o que poderia, em tese, também modificar a temperatura superficial do dente.

Quanto ao emprego do gás refrigerante no diagnóstico clínico da vitalidade pulpar, observa-se que as substâncias refrigerantes, como um todo, ao serem utilizadas na forma de aerossol, invariavelmente promovem na superfície dentária um decréscimo acentuado da temperatura, de modo rápido e intenso, e em conseqüência, fornecem respostas mais seguras e confiáveis (AUN et al., 1994). Por estas razões, o gás refrigerante (DDM) foi o teste térmico de eleição para este estudo.

Em relação à aplicação do teste com gás refrigerante $\left(\right.$ Endofrost $\left.^{\circledR}\right)$, o gás foi borrifado em hastes flexíveis de algodão $\left(\right.$ Cotonete $^{\circledR}$ ) com o intuito de padronizar a área do aplicador em todos os dentes (JONES, 1999), o que não ocorreria com a aplicação de um teste como o lápis ou bastão de gelo, que, após contatar a superfície do esmalte, inicia um processo de fusão, entrando em fase líquida que avança em todos os sentidos da superfície da coroa, alcançando inclusive o periodonto.

A área de aplicação das hastes de algodão é semelhante a $5 \mathrm{~mm}^{2}$, o que facilita inclusive a análise pelo software que acompanha a câmera termográfica.

O software da câmera infravermelha analisa as imagens de acordo com a área determinada pelo operador. Dentro dessa área selecionada serão localizados 
os chamados hot spots e os cold spots e a partir dessa seleção será iniciada a análise dos dados. Justifica-se dessa forma a necessidade de padronização do aplicador do estímulo, o que não é notado nos estudos preliminares (KELLS 2000b; POGREL; YEN; TAYLOR, 1989)

O tempo de aplicação na face vestibular foi estipulado em 2 segundos por se tratar de um tempo suportável para a sensibilização do paciente, sem que houvesse movimentação da cabeça em resposta ao estímulo doloroso.

No mais, a literatura mostra que o tempo de resposta a um estímulo térmico em superfície intacta de esmalte varia entre 0.72 e 5.08 segundos, dependendo do método usado, do dente testado e idade do paciente (LINSUWANONT et al., 2007).

Este fato foi também comprovado por Caldeira (1998), que obteve, em dentes sadios, $0.88 \mathrm{~s}$ para resposta à aplicação de gás refrigerante na faixa etária de $10 \mathrm{a}$ 20 anos, 1.23 s para 21 a 50 anos e 1.75 s para pacientes acima de 51 anos.

Para maior padronização dos dados, os pacientes submetidos aos testes tinham idade entre 27 e 38 anos, para eliminação de alguns fatores que pudessem modificar a resposta ao estímulo como aumento de espessura esmalte/dentina decorrente de idade mais avançada. No mais, os dentes selecionados para a análise não possuíam restaurações na área de aplicação do estímulo para que a condutibilidade térmica do esmalte não fosse mascarada pela condutibilidade de materiais restauradores.

Os resultados desse estudo contradizem o esperado, pois não foi notada diferença significante na temperatura da superfície do esmalte de dentes que sofreram tratamento endodôntico (entenda-se com ausência de vascularização interna) e dentes com vitalidade pulpar. 
Ainda neste rumo, a semelhança entre as faixas de temperatura mínima e máxima encontradas nos dentes estudados com e sem a utilização do lençol de borracha para isolamento absoluto sugere que os resultados não foram mascarados por trocas de temperatura com o meio ou tecidos de suporte. No entanto, algumas tomadas apresentaram valores duvidosos de temperatura, talvez devido à manipulação indevida dos dados no software de análise, ou até mesmo no momento da tomada. As planilhas com esse tipo de informação foram eliminadas do estudo.

Ao analisar a capacidade de transmissão do estímulo térmico frio até a parede vestibular interna, sabe-se que o tempo de resposta inicial ao teste é sempre menor àquele obtido até que ocorra a troca da temperatura na parede vestibular da câmara pulpar (CALDEIRA, 1998).

Pode-se ainda pressupor a movimentação de fluídos dentinários antes da detecção de alteração de temperatura da parede vestibular interna, fato discutido pela teoria hidrodinâmica (FUSS et al., 1986; TROWBRIDGE et al., 1980).

Mesmo assim, a relação entre a sensibilização do paciente, distribuição da temperatura na estrutura dental e circulação de fluídos dentinários não é de total consenso na literatura.

Sabe-se que, no momento em que a superfície da coroa de um dente recebe a estimulação térmica, o esmalte pode contrair ou expandir antes que a dentina sofra alteração de temperatura. A compressão ou expansão dessa dentina pode resultar em deslocamento de fluídos no interior dos túbulos dentinários antes que o efeito principal dessa expansão ou contração se inicie (LINSUWANONT; PALAMARA; MESSER, 2007). 
Este detalhe parece importante, pois podem ocorrer variações na superfície do esmalte quanto à temperatura se este tecido estiver mais ou menos hidratado, ou seja, a princípio, em dentes vitais ou não vitais.

Pode-se esperar, num primeiro instante, que dentes desidratados poderiam ter a transmissão do estímulo térmico frio diminuída entre esmalte e dentina, pela ausência de fluido tubular. Isto poderia acontecer também em dentes de pacientes senis, onde a mineralização é mais presente, e tanto o diâmetro dos túbulos como o volume do fluido estão diminuídos.

No primeiro caso não foi observada diferença entre os dentes com ou sem vitalidade, o que induz mais uma vez à pressuposição de que a temperatura não é dissipada em profundidade, mas sim de modo linear pela superfície.

De modo geral, estudos de análise de temperatura da superfície externa de dentes mostram que a temperatura mínima ou máxima provocada pelos testes térmicos acontece no primeiro segundo após a estimulação e a contração ou expansão do esmalte acontece antes que a temperatura atinja a camada de dentina.

método proposto analisa apenas a temperatura superficial da camada de esmalte do dente. Portanto, resta a dúvida se um dente com quadro alteração inflamatória pulpar irreversível pode ser diagnosticado através da imagem infravermelha. Ou seja, se o aumento da temperatura do tecido pulpar provocado pela reação inflamatória é de alguma forma, conduzido a superfície de esmalte a ponto de ser notada diferença na temperatura da superfície coronária de um dente.

A imagem infravermelha torna-se momentaneamente difícil de ser utilizada na clínica diária em virtude da complexidade do método. Novos estudos devem ser encaminhados na utilização de outros modelos de câmera, inclusive portáteis, passíveis de um protocolo de utilização facilitado. 


\section{CONCLUSÕES}

De acordo com a análise dos resultados, pode-se afirmar que não existe diferença significante entre as temperaturas da superfície da coroa de dentes portadores de polpa vital e dentes tratados endodonticamente.

O uso do isolamento absoluto torna-se opcional para a análise termográfica desde que a temperatura ambiente seja estável.

A termografia infravermelha é um método preciso para mensuração da temperatura de coroas dentárias, no entanto apresenta algumas limitações clínicas que precisam ser superadas. 


\section{REFERÊNCIAS ${ }^{5}$}

Abrão CV. A oximetria de pulso como recurso auxiliar na determinação da vitalidade pulpar de dentes permanentes traumatizados [Dissertação de Mestrado]. São Paulo: Faculdade de Odontologia da USP; 2006.

Aun CE, Caldeira CL, Gavini G, Pesce HF. Avaliação da vitalidade pulpar em dentes permanentes jovens com rizogênese completa. Rev Odontol FZL 1992;4(2): 95-104.

Aun CE, Caldeira CL, Gavini G, Pesce HF. Avaliação da vitalidade pulpar em dentes permanentes jovens com rizogênese incompleta. Rev Paul Odontol 1994; 16(6):9-16.

Austin LT, Waggener DT. Vitality tests with particular reference to the use of ice. J Am Dent Assoc 1941;28(7):1044-9.

Baume L. Diagnosis of diseases of the pulp. Oral Surg Oral Med Oral Pathol 1970;29(1):102-16.

Berger CR. Avaliação clínica do teste de vitalidade pulpar com gelo seco. Odontol Mod 1986;13(8):6-13.

Bernick S. Differences in nerve distribution between erupted and non - eupted human teeth. J Dent Res 1964;43(3):406-11.

Bernick S. Effect of ageing on the nerve supply to human teeth. J Dent Res 1967;46(4):694-99.

Bernick S. Vascular and nerve changes associated with the healing of human pulp. Oral Surg Oral Med Oral Pathol 1972;33(6):983-1000.

Beveridge EE, Brown AC. Measurement of human dental pulp pressure and its response to clinical variables. Oral Surg 1965;19:655.

\footnotetext{
${ }^{5}$ De acordo com Estilo Vancouver. Abreviatura de periódicos segundo base de dados MEDLINE.
} 
Bhaskar SN, Rappaport HM. Dental vitality tests and pulp status. J Am Dent Assoc 1973;86(2):409-11.

Boggett D, Blond J, Rolfe P. Laser Doppler measurements of blood flow in skin tissue. Biomed Eng 1985;7(3):225-32.

Brannstrom M, Linden LA, Astrom A. The hydrodynamics of the dentinal tubule and of pulp fluid. A discussion of this significance in relation to dentinal sensitivity. Caries Res 1967;1(1):310- 7.

Burns RC, Cohen S. Caminhos da polpa. Rio de Janeiro: Guanabara Koogan; 2000.

Caldeira CL, Fidel, SR, Pesce HF, Aun CE. Avaliação da resposta pulpar aos testes de vitalidade pulpar com frio em dentes com deposição de dentina reparativa. RPG 1995;2(3):157-60.

Caldeira CL. Avaliação clínica da resposta pulpar obtida em pacientes submetidos aos testes de vitalidade com frio (gelo e diclorodifluorometano) em função da faixa etária e grupo dentário [ Dissertação de Mestrado]. São Paulo. Faculdade de Odontologia da USP, 1997.

Caldeira CL, Aun CE. Avaliação da temperatura produzida pelos gases refrigerantes na interface dentina-polpa. Anais da Soc Bra Pesq Odontol 1996;13:25.

Caldeira CL. Relação entre o tempo de resposta sensorial e a temperatura observada internamente na parede vestibular quando da aplicação do tetrafluoroetano como teste de sensibilidade pulpar [Tese de Doutorado]. São Paulo: Faculdade de Odontologia da USP; 1998.

Caldeira CL, Suzuki M, Bezerra AG, Gavini G, Aun CE. Observações sobre a utilização da oximetria de pulso em dentes traumatizados. Rev Assoc Paul Cir Dent 2007;61:187-94.

Calil E. Determinação da vitalidade pulpar in vivo através da oximetria de pulso [Dissertação de Mestrado]. São Paulo: Faculdade de Odontologia da USP; 2003.

Cave SG, Freer TJ, Podlich HM. Pulp-test responses in orthodontic patients. Aust Orthod J 2002;18(1):27-34. 
Chambers IG. The role and methods of pulp testing in oral diagnosis: a review. Int Endod J 1982;15(1):1-15.

Crandell CE, Hill RP. Thermography in Dentistry. Oral Surg 1966;21:316.

Dachi SF, Haley JV, Sanders JE. Standardization of a test for dental sensitivity to cold. Oral Surg Oral Med Oral Pathol 1967;24(5):687-92.

Dummer PMH, Hicks R, Huws D. Clinical signs and symptoms in pulp disease. Int Endod J 1980;13:27-35.

Ehrmann EH. Pulp testers and pulp testing with particular reference to the use of dry ice. Aust Dent J 1977;22(4):272-9.

Estrela C. Ciência endodôntica. São Paulo: Artes Médicas; 2004.

Evans D, Reid J, Strang R, Stirrups D. A comparision of laser Doppler flowmetry with other methods of assessing the vitality of traumatized anterior teeth. Endod Dent Traumatol 1999;15(6):284-90.

Fanibunda KB. A laboratory study to investigate the differentiation of pulp vitality in human teeth by temperature measurement. J Dent 1985;13(4):295-303.

Fanibunda KB. Diagnoses of tooth vitality by crown surface temperature measurement: a clinical evaluation. J Dent 1986a;14(4):160-4

Fanibunda KB. The feasibility of temperature measurement as a diagnostic procedure in human teeth. J Dent 1986b;14(3):126-9.

Fearnhead RW. The histological demonstration of nerve fibers in human dentin. Oxford: Pergamon Press; 1963.

Fried K. Changes in pulpal nerves with aging. Proc Finn Dent Soc 1992;88(1): 517-28. 
Fuss Z, Trowbridge H, Bender I, Rickoff B, Sorin S. Assesment or reliability of electrical and thermal pulp testing agents. J Endod 1986;12(7):301-5.

Gazelius B, Olgart L, Edwall L. Non-invasive recording of blood flow in human dental pulp. Endod Dent Traumatol 1986;2(5):219-21.

Gazelius B, Olgart L, Edwall B . Restored vitality in luxated teeth assessed by laser Doppler flowmeter. Endod Dent Traumatol 1988;4(6):265-8.

Goodies HE, Winthrop V, Whitw JM. Pulpal responses to cooling tooth temperatures. J Endod 2000;26(5):263-7.

Gopikrishna V, Tinagupta K, Kandaswamy D. Comparison of electrical, thermal, and pulse oximetry methods for assessing pulp vitality in recently traumatized teeth. J Endod 2007;33(5):531-5.

Grayson AS. A new electric pulp vitality tester. Quintessence Int Dent Dig 1977; 8(3):79-82.

Hietanen J, Rantanen AV. Screening some modern pulp vitality testers. Proc Finn Dent Soc 1973;69(5):173-81.

Howell RM, Duell RC, Mullaney TP. The determination of pulp vitality by thermographic means using cholesteric liquid crystals. Oral Surgery Oral Med Oral Pathol 1970;29(5):763-8.

Hussey DL, Biagioni PA, Lamey PJ. Thermographic measurement of temperature change during resin composite polymerization in vivo. J Dent 1995;23(5):267-71.

Hussey DL, Biagioni PA, Mccullagh JJP, Lamey PJ. Thermographic assessment of heat generated on the root surface during post space preparation. Int Endod $\mathrm{J}$ 1997;30(3):187-90.

Hyman JJ, Cohen ME. The predictive value of endodontic diagnostic tests. J Oral Surg 1984;58(3):343-6.

Ingolfsson ER, Tronstad L, Hersh, E, Riva, CE. Efficacy of laser Doppler flowmetry in determining pulp vitality of human teeth. Endod Dent Traumatol 1994;10(2):83-7. 
Ikawa M, Horiuchi H, Ikawa K. Optical characteristcs of humam extracted teeth and possible application of photo plethymography to the human pulp. J Arch Oral Biol 1994;39(10):821-7.

Ikawa M, Vongsavan N.,Horiuchi, H. Scattering of laser light directed onto the labial surface of extracted human upper central incisors. J Endod 1999;25(7):4835.

Jack L. Observation of the relation of thermal irritation of the teeth to their treatment. Dental Cosmos 1899;41(1):1-6.

Jones DM. Effect of the type carrier used on the results of

dichlorodifluoromethane application to teeth. J Endod 1999;25(10):692-4.

Kahan RS, Gulabilava K, Snook M, Setcell DJ. Evaluation of a pulse oximeter and customized probe for pulp vitality testing. J Endod 1996;22(3):105-9.

Kells BE, Kennedy JG, Biagioni PA, Lamey PJ. Computerized infrared thermographic imaging and pulpal blood flow: Part 2. Rewarming of healthy human teeth following a controlled cold stimulus. Int Endod J 2000b;33(5):448-62.

Kells BE, Kennedy JG, Biagioni PA, Lamey PJ. Computerized infrared thermographic imaging and pulpal blood flow: Part 1. A protocol for thermal imaging of human teeth. Int Endod J 2000a; 33(5):442-7.

Kidd JF, Vickers MD. Pulse oximeters: essential monitors with limitations. $\mathrm{Br} \mathrm{J}$ Anaesth 1989;62(4):355-7.

Linde A. Dentine and dentinogenesis. Boca Raton, FL: CRC Press Inc; 1984.

Linsuwanont J, Palamara JE, Messer $\mathrm{HH}$. An investigation of thermal stimulation in intact teeth. Arch Oral Biol 2007;52(3):218-27.

Lipski M. In vitro infrared thermographic assessment of root surface temperatures generated by high-temperature thermoplasticized injectable gutta-percha obturation technique. J Endod 2006;32(5):438-41. 
Lundy T, Stanley HR. Correlation of pulpal histopathology and clinical symptoms in human teeth subject to experimental irritation. Oral Surg Oral Med Oral Pathol 1969; 27(2):187-201.

Mc Cullagh JJP, Setchell DJ, Gulabivala K, Hussey DL, Biagioni P, Lamey P-J, et al. A comparison of thermocouple and infrared thermographic analysis of temperature rise on the root surface during the continuous wave of condensation technique. Int Endod J 2000;33(4):326-32.

Medeiros JMF, Pesce HF. Contribuição ao estudo de alguns aspectos da histofisiologia pulpar de interesse endodôntico [Trabalho de Conclusão de Curso]. São Paulo: Faculdade de Odontologia da USP;, 1980.

Medeiros JMF, Pesce HF. Estudo comparativo in vivo de dois agentes térmicos (gelo e diclorodifluorometano) quanto à sua confiabilidade na detecção da vitalidade pulpar em dentes caninos humanos íntegros pertencentes a pacientes de ambos os sexos. Rev Paul Odontol 1993;15(2):18-24.

Mendis BR, Darling AL. Distribution with age and attrition of peritubular dentine in the crowns of human teeth. Arch Oral Biol 1979;24(2):131-9.

Mickel AK, Lindquist KA, Chogle S, Jones JJ, Curd F. Electric pulp tester conductance through various interface media. J Endod. 2006;32(12):1178-80.

Mills RW. Pulse oximetry: a method of vitality testing for teeth. Br Dent $\mathrm{J}$ 1992;172(9):334-5.

Mjor IA, Nordahl I. The density and branching of dentinal tubules in human teeth. Arch Oral Biol 1996;41(5):401-12.

Mumford JM. Pain perception threshold on stimulating human teeth and the histological condition of the pulp. Br Dent J. 1967;123(7):427-33.

Mumford JM. Endodontics - The diagnosis of pulp disease and its sequelae. Pergamom Press; 1984.

Nicholas JV, White DR.Termometria de termopares"- Temperaturas Rastreáveis. Chichester: John Wiley \& Sons Ltd.; 1994. 
Nissan R, Trope Mzhang C, Chance B. Dual wavelength spectrophotometry as a diagnostic test of the pulp chamber contents. Oral Surg Oral Med Oral Pathol 1992;74(4):508-14.

Noblett WC, Wilcox LR, Scamman F, Johnson WT, Diaz- Arnold A. Detection of pulpar circulation in vitro by pulse oximetry. J Endod 1996;22(1):1-5.

Nogueira ALF. Laser doppler como meio diagnóstico para vitalidade pulpar : estabelecimento de parâmetros de leitura [Dissertação de Mestrado]. São Paulo: Faculdade de Odontologia da USP; 2003.

Odor TM, Chandler NP, Watson TF, Pitt Ford TR, Mc DONALD F. Laser light transmission in teeth: a study of the patterns in different species. Int Endod $\mathrm{J}$ 1999;32(4):296-302.

Olgart LM. Pain research using feline teeth. J Endod 1986;12(10):458-61.

Paiva JG, Antoniazzi JH. Endodontia: bases para a prática clínica. 2 ed. São Paulo: Artes Médicas; 1988.

Pashley DH. Smear layer: physiological considerations. Oper Dent 1984;3:13-29.

Pashley $\mathrm{DH}$. The dentin - predentin complex and its permeability: physiologic review. J Dent Res 1985;64:613-20.

Pashley DH. Dentin permeability and dentin sensitivity. Proc Finn Dent Soc 1992;88(1):31-7.

Pesce HF, Medeiros JFM, Risso VA. Determinação da vitalidade pulpar pelo teste térmico do frio. (Contribuição ao estudo). Rev Paul Odontol 1985;7(5):2-10.

Pesce HF, Barletta FB, Medeiros JMF, Machado, MEL. Avaliaçäo in vitro dos efeitos de três testes pulpares térmicos sobre a temperatura intrapulpar. Rev. Odontol UNICID 1995;7(1):7-11.

Petterson K, Soderstrom C, Kiani-Anaraki M, Levy G. Evaluation of the ability of thermal and electrical tests to register pulp vitality. Endod Dent Traumatol 1999; 15(3):127-31. 
Pitt Ford TR, Rowe AHR. The assessment of pulpal vitality. Int Endod J 1990; 23(2):77-83.

Pogrel MA, Yen CK, Taylor RC.Studies in tooth crown temperature gradients with the use of infrared thermography.Oral Surg Oral Med Oral Pathol 1989; 67(5):583-7.

Pulver WH, Korzen BH. Endodontic diagnosis. Ont Dent 1978;55(4):13-7.

Radhakrishnan S, Munshi AK, Hegde AM. Pulse oximetry: a diagnostic instrument in pulpal vitality testing. J Clin Pediatr Dent 2002;26(2):141-5.

Reynolds RL. The determination of pulp vitality by means of thermal and electrical stimuli. OralSurg Oral Med Oral Pathol 1966;22(2):231-40.

Ribeiro AC, Nogueira GE, Antoniazzi JH, Moritz A, Zezell DM. Effects of diode laser $(810 \mathrm{~nm})$ irradiation on root canal walls: thermographic and morphological studies. J Endod 2007;33(3):252-5.

Robinson HGB. The nature of the diagnostic process. Dent Clin N Am 1963:3-8.

Schnettler JM, Wallace JA. Pulse oximetry as a diagnostic tool of pulpal vitality. Endod J 1991;17:448-90.

Smith E, Dickson M, Evans AL, Smith D, Murray CA. An evaluation of the use of tooth temperature to assess human pulp vitality. Int Endod J 2004;37:374-80.

Trowbridge HO, Franks M, Korostoff E, Emling R. Sensory response to thermal stimulation in human teeth. J Endod 1980;6(1):405-12.

Van Hassel HJ, Brown AC. Effect of temperature changes on intrapulpal pressure and hydraulic permeability in dogs. Arch Oral Biol 1969;14(3):301-15.

Von Eifinger FF. Sensibilitatstest am meschilischen zahn mit kalteareosolen. Dtsch Zahnarztebl 1970;24(1):26-32.

Walton RE, Torabinejad M. Princípios e prática em endodontia. $2^{a}$ ed. São Paulo: Livraria Santos; 1997. 
Weber DF, Zaki AE. Scanning and transmission electron microscopy of tubular structures presumed to be human odontoblast processes. J Dent Res 1986; 65(7):982-6.

Wilder-Smith PEEB. A new method for the non-invasive measurement of pulpal blood flow. Int Endod J 1988;21(5):307-12. 
ANEXO A - Parecer do Comitê de Ética em Pesquisa da FOUSP

\section{UNIVERSIDADE DE SÃO PAULO \\ FACULDADE DE ODONTOLOGIA}

\section{PARECER DE APROVAÇÃO \\ Protocolo 121/07}

Com base em parecer de relator, o Comitê de Ética em Pesquisa APROVOU o protocolo de pesquisa "DETERMINAÇÃO DA VITALIDADE PULPAR IN VIVO ATRAVÉS DA TERMOGRAFIA INFRAVERMELHA", de responsabilidade da Pesquisadora ISABELLE ELIAS, sob orientação do Professor Doutor CELSO LUIZ CALDEIRA.

Tendo em vista a legislação vigente, devem ser encaminhados a este Comitê relatórios anuais referentes ao andamento da pesquisa e ao término cópia do trabalho em "cd". Qualquer emenda do projeto original deve ser apresentada a este CEP para apreciação, de forma clara e sucinta, identificando a parte do protocolo a ser modificada e suas justificativas.

São Paulo, 04 de dezembro de 2007

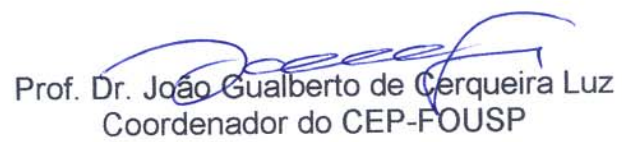

Av. Prof. Lineu Prestes, 2227 - Cidade Universitária "Armando de Salles Oliveira" CEP 05508-900 São Paulo - SP - Diretoria Telefax: (011) 3091- 0062/3091-7817/3091-7860 - Compras (011) 3091-7895 Impresso no S.0.0. 
APÊNDICE A - Ficha Clínica do Paciente

Paciente:

Idade: anos.

Sexo: Feminino $\square \quad$ Masculino $\square$

Dente Analisado:

Presença de restauração: $\operatorname{SIM} \square$ NÃO

Tempo de resposta ao teste térmico: seg. 
APÊNDICE B - Termo de Consentimento Livre e Esclarecido

Sr. Paciente,

Esta pesquisa determinada "Determinação da vitalidade pulpar in vivo através da termografia infravermelha" será realizada para que possamos identificar quais dentes necessitam maiores estímulos frios do que outros, com a finalidade de esclarecer qual o tempo necessário da resposta ao frio para que um dente seja considerado com problema de canal.

Realizaremos procedimentos comuns a qualquer diagnóstico dental, que envolvem a tomada de uma radiografia e a aplicação de um teste com frio (um gás refrigerante) para identificar se existe uma sensibilidade mais aumentada que o comum.

Neste momento você poderá sentir uma sensibilidade, leve, imediata e não superior a alguns segundos, o que nos mostrará o quanto o dente está ou não com o canal comprometido.

Após a realização desses procedimentos, utilizaremos uma câmera infravermelha para captação da imagem do seu dente, nesse momento você não sentirá nada.

Identificando alterações em seus dentes que indiquem a necessidade de tratamento endodôntico (de canal) você será encaminhado (a) a uma pessoa capacitada a realizá-lo.

A sua participação nesta pesquisa não é obrigatória, portanto você pode se retirar a qualquer momento sem nenhuma penalização de sua parte; independente de sua decisão, seu atendimento na faculdade de odontologia estará assegurado.

Todas as informações, relativas a dados confidenciais sobre sua pessoa, serão mantidas em sigilo absoluto, assim como qualquer dano decorrente de procedimentos realizados durante a pesquisa serão de total responsabilidade do pesquisador.

Concordo em participar da pesquisa,

Nome:

Assinatura

Data:

Responsável pela pesquisa:

C.D. Isabelle Elias 
APÊNDICE C - Valores originais de variação de temperatura $(\Delta T)$ obtidos nas tomadas de estimulação com gás refrigerante com a utilização de isolamento absoluto, expressos em Graus Celsius.

C.1 PV 1 - Dente portador de polpa vital.

\begin{tabular}{|c|c|}
\hline PV & \\
\hline Tempo (s) & Temperatura $(\Delta \mathrm{T})$ \\
\hline 1 & 0 \\
\hline$-0,65$ & 0 \\
\hline$-0,5$ & 0 \\
\hline 0,2 & 0 \\
\hline 0,4 & $-39,198$ \\
\hline 0,6 & $-40,118$ \\
\hline 0,8 & $-40,118$ \\
\hline 1 & $-40,334$ \\
\hline 1,2 & $-40,615$ \\
\hline 1,4 & $-40,959$ \\
\hline 1,6 & $-41,001$ \\
\hline 1,8 & $-40,927$ \\
\hline 2 & $-40,948$ \\
\hline 2,2 & $-40,886$ \\
\hline 2,4 & $-41,242$ \\
\hline 2,6 & $-40,844$ \\
\hline 2,8 & $-17,935$ \\
\hline 3 & $-15,44$ \\
\hline 3,2 & $-13,563$ \\
\hline 3,4 & $-12,027$ \\
\hline 3,6 & $-10,798$ \\
\hline 3,8 & $-9,846$ \\
\hline 4 & $-9,067$ \\
\hline 4,2 & $-8,218$ \\
\hline 4,4 & $-7,651$ \\
\hline 4,6 & $-7,035$ \\
\hline 4,8 & $-6,544$ \\
\hline 5 & $-6,044$ \\
\hline 5,2 & $-5,659$ \\
\hline 5,4 & $-5,241$ \\
\hline 5,6 & $-4,908$ \\
\hline 5,8 & $-4,535$ \\
\hline 6 & $-4,222$ \\
\hline 6,2 & $-3,962$ \\
\hline 6,4 & $-3,703$ \\
\hline 6,6 & $-3,445$ \\
\hline 6,8 & $-3,256$ \\
\hline 7 & $-3,028$ \\
\hline 7,2 & $-2,886$ \\
\hline 7,4 & $-2,744$ \\
\hline 7,6 & $-2,591$ \\
\hline
\end{tabular}

\begin{tabular}{|c|c|}
\hline 7,8 & $-2,461$ \\
\hline 8 & $-2,354$ \\
\hline 8,2 & $-2,23$ \\
\hline 8,4 & $-2,174$ \\
\hline 8,6 & $-2,05$ \\
\hline 8,8 & $-1,972$ \\
\hline 9 & $-1,876$ \\
\hline 9,2 & $-1,781$ \\
\hline 9,4 & $-1,675$ \\
\hline 9,6 & $-1,602$ \\
\hline 9,8 & $-1,569$ \\
\hline 10 & $-1,558$ \\
\hline 10,2 & $-1,513$ \\
\hline 10,4 & $-1,463$ \\
\hline 10,6 & $-1,418$ \\
\hline 10,8 & $-1,374$ \\
\hline 11 & $-1,374$ \\
\hline 11,2 & $-1,29$ \\
\hline 11,4 & $-1,229$ \\
\hline 11,6 & $-1,207$ \\
\hline 11,8 & $-1,196$ \\
\hline 12 & $-1,168$ \\
\hline 12,2 & $-1,174$ \\
\hline 12,4 & $-1,157$ \\
\hline 12,6 & $-1,14$ \\
\hline 12,8 & $-1,096$ \\
\hline 13 & $-1,107$ \\
\hline 13,2 & $-1,096$ \\
\hline 13,4 & $-1,085$ \\
\hline 13,6 & $-1,063$ \\
\hline 13,8 & $-1,057$ \\
\hline 14 & $-1,018$ \\
\hline 14,2 & $-1,068$ \\
\hline 14,4 & $-1,052$ \\
\hline 14,6 & $-1,057$ \\
\hline 14,8 & $-0,935$ \\
\hline 15 & $-0,93$ \\
\hline
\end{tabular}


C.2 PV 2 - Dente portador de polpa vital.

\begin{tabular}{|c|c|}
\hline$\overline{\mathbf{P V}}$ & \\
\hline Tempo (s) & Temperatura $(\Delta T)$ \\
\hline$-3,3$ & 0 \\
\hline$-3,1$ & $-0,022$ \\
\hline$-2,9$ & $-0,028$ \\
\hline$-2,7$ & 0,016 \\
\hline$-2,5$ & 0,044 \\
\hline$-2,3$ & 0,093 \\
\hline$-2,1$ & 0,099 \\
\hline$-1,9$ & 0,093 \\
\hline$-1,7$ & 0,077 \\
\hline$-1,5$ & 0,071 \\
\hline$-1,3$ & 0,082 \\
\hline$-1,1$ & 0,071 \\
\hline$-0,9$ & 0,077 \\
\hline$-0,7$ & 0,066 \\
\hline$-0,5$ & 0,011 \\
\hline$-0,3$ & $-0,011$ \\
\hline$-0,1$ & $-0,022$ \\
\hline 0,1 & $-0,028$ \\
\hline 0,3 & $-0,056$ \\
\hline 0,5 & $-0,028$ \\
\hline 0,7 & $-0,183$ \\
\hline 0,9 & $-0,715$ \\
\hline 1,1 & $-37,887$ \\
\hline 1,3 & $-37,917$ \\
\hline 1,5 & $-37,877$ \\
\hline 1,7 & $-37,957$ \\
\hline 1,9 & $-38,068$ \\
\hline 2,1 & $-38,32$ \\
\hline 2,3 & $-38,229$ \\
\hline 2,5 & $-38,461$ \\
\hline 2,7 & $-38,471$ \\
\hline 2,9 & $-38,35$ \\
\hline 3,1 & $-38,249$ \\
\hline 3,3 & $-37,697$ \\
\hline 3,5 & $-16,783$ \\
\hline 3,7 & $-14,637$ \\
\hline 3,9 & $-13,293$ \\
\hline 4,1 & $-12,361$ \\
\hline 4,3 & $-11,274$ \\
\hline 4,5 & $-10,503$ \\
\hline 4,7 & $-9,906$ \\
\hline 4,9 & $-9,414$ \\
\hline 5,1 & $-8,888$ \\
\hline 5,3 & $-8,359$ \\
\hline 5,5 & $-7,903$ \\
\hline 5,7 & $-7,418$ \\
\hline 5,9 & $-6,968$ \\
\hline 6,1 & $-6,604$ \\
\hline
\end{tabular}

\begin{tabular}{|c|c|}
\hline 6,3 & $-6,225$ \\
\hline 6,5 & $-5,901$ \\
\hline 6,7 & $-5,698$ \\
\hline 6,9 & $-5,472$ \\
\hline 7,1 & $-5,258$ \\
\hline 7,3 & $-5,11$ \\
\hline 7,5 & $-4,951$ \\
\hline 7,7 & $-4,792$ \\
\hline 7,9 & $-4,586$ \\
\hline 8,1 & $-4,486$ \\
\hline 8,3 & $\begin{array}{l}-4,34 \\
\end{array}$ \\
\hline 8,5 & $-4,164$ \\
\hline 8,7 & $-4,019$ \\
\hline 8,9 & $-3,925$ \\
\hline 9,1 & $-3,78$ \\
\hline 9,3 & $-3,658$ \\
\hline 9,5 & $-3,542$ \\
\hline 9,7 & $-3,398$ \\
\hline 9,9 & $-3,352$ \\
\hline 10,1 & $-3,248$ \\
\hline 10,3 & $-3,156$ \\
\hline 10,5 & $-3,104$ \\
\hline 10,7 & $-2,989$ \\
\hline 10,9 & $-2,874$ \\
\hline 11,1 & $-2,782$ \\
\hline 11,3 & $-2,737$ \\
\hline 11,5 & $-2,685$ \\
\hline 11,7 & $-2,599$ \\
\hline 11,9 & $-2,508$ \\
\hline 12,1 & $-2,44$ \\
\hline 12,3 & $-2,411$ \\
\hline 12,5 & $-2,417$ \\
\hline 12,7 & $-2,388$ \\
\hline 12,9 & $-2,326$ \\
\hline 13,1 & $-2,337$ \\
\hline 13,3 & $-2,343$ \\
\hline 13,5 & $-2,36$ \\
\hline 13,7 & $-2,354$ \\
\hline 13,9 & $-2,314$ \\
\hline 14,1 & $-2,235$ \\
\hline 14,3 & $-2,149$ \\
\hline 14,5 & $-2,064$ \\
\hline 14,7 & $-2,047$ \\
\hline 14,9 & $-2,03$ \\
\hline 15,1 & $-1,957$ \\
\hline
\end{tabular}


C.3 PV 3 - Dente portador de polpa vital.

\begin{tabular}{|c|c|}
\hline PV & \\
\hline Tempo (s) & Temperatura $(\Delta \mathrm{T})$ \\
\hline 0,2 & 0,13617 \\
\hline 0,4 & 0,14717 \\
\hline 0,6 & 0,06417 \\
\hline 0,8 & $-0,10283$ \\
\hline 1 & $-0,13083$ \\
\hline 1,2 & $-0,11383$ \\
\hline 1,4 & $-30,72683$ \\
\hline 1,6 & $-34,30883$ \\
\hline 1,8 & $-34,48983$ \\
\hline 2 & $-34,82383$ \\
\hline 2,2 & $-35,00583$ \\
\hline 2,4 & $-35,14083$ \\
\hline 2,6 & $-35,23683$ \\
\hline 2,8 & $-35,19783$ \\
\hline 3 & $-35,19783$ \\
\hline 3,2 & $-35,25583$ \\
\hline 3,4 & $-35,18883$ \\
\hline 3,6 & $-10,10583$ \\
\hline 3,8 & $-8,24183$ \\
\hline 4 & $-6,86483$ \\
\hline 4,2 & $-5,93583$ \\
\hline 4,4 & $-5,05983$ \\
\hline 4,6 & $-4,43683$ \\
\hline 4,8 & $-3,97183$ \\
\hline 5 & $-3,55083$ \\
\hline 5,2 & $-3,12583$ \\
\hline 5,4 & $-2,80183$ \\
\hline 5,6 & $-2,50783$ \\
\hline 5,8 & $-2,23183$ \\
\hline 6 & $-2,11183$ \\
\hline 6,2 & $-1,99783$ \\
\hline 6,4 & $-1,79783$ \\
\hline 6,6 & $-1,63283$ \\
\hline 6,8 & $-1,43983$ \\
\hline 7 & $-1,30383$ \\
\hline 7,2 & $-1,16283$ \\
\hline 7,4 & $-1,06083$ \\
\hline 7,6 & $-0,98783$ \\
\hline 7,8 & $-0,90283$ \\
\hline 8 & $-0,91483$ \\
\hline 8,2 & $-0,91983$ \\
\hline 8,4 & $-0,85783$ \\
\hline 8,6 & $-0,86983$ \\
\hline 8,8 & $-0,84683$ \\
\hline 9 & $-0,82983$ \\
\hline 9,2 & $-0,80183$ \\
\hline 9,4 & $-0,79083$ \\
\hline 9,6 & $-0,84083$ \\
\hline
\end{tabular}

\begin{tabular}{|c|c|}
\hline 9,8 & $-0,79583$ \\
\hline 10 & $-0,84683$ \\
\hline 10,2 & $-0,82483$ \\
\hline 10,4 & $-0,81883$ \\
\hline 10,6 & $-0,84683$ \\
\hline 10,8 & $-0,81883$ \\
\hline 11 & $-0,80183$ \\
\hline 11,2 & $-0,73983$ \\
\hline 11,4 & $-0,69483$ \\
\hline 11,6 & $-0,70083$ \\
\hline 11,8 & $-0,71183$ \\
\hline 12 & $-0,72283$ \\
\hline 12,2 & $-0,69483$ \\
\hline 12,4 & $-0,67283$ \\
\hline 12,6 & $-0,58283$ \\
\hline 12,8 & $-0,56583$ \\
\hline 13 & $-0,54383$ \\
\hline 13,2 & $-0,50983$ \\
\hline 13,4 & $-0,49883$ \\
\hline 13,6 & $-0,54383$ \\
\hline 13,8 & $-0,58283$ \\
\hline 14 & $-0,57783$ \\
\hline 14,2 & $-0,51583$ \\
\hline 14,4 & $-0,51583$ \\
\hline 14,6 & $-0,48183$ \\
\hline 14,8 & $-0,51583$ \\
\hline 15 & $-0,52683$ \\
\hline
\end{tabular}


C.4 DT 1 - Dente tratado endodonticamente.

\begin{tabular}{|c|c|}
\hline DT & \\
\hline Tempo (s) & $\begin{array}{c}\text { Temperatura } \\
(\Delta \mathbf{T})\end{array}$ \\
\hline$-1,3$ & 0 \\
\hline$-1,1$ & $-0,038$ \\
\hline$-0,9$ & 0,011 \\
\hline$-0,7$ & 0,027 \\
\hline$-0,5$ & 0,038 \\
\hline$-0,3$ & 0,081 \\
\hline$-0,1$ & 0,156 \\
\hline 0,1 & 0,183 \\
\hline 0,3 & 0,156 \\
\hline 0,5 & 0,167 \\
\hline 0,7 & 0,021 \\
\hline 0,9 & $-0,054$ \\
\hline 1,1 & $-0,065$ \\
\hline 1,3 & $-0,184$ \\
\hline 1,5 & $-20,712$ \\
\hline 1,7 & $-28,552$ \\
\hline 1,9 & $-36,563$ \\
\hline 2,1 & $-37,201$ \\
\hline 2,3 & $-37,412$ \\
\hline 2,5 & $-37,73$ \\
\hline 2,7 & $-38,118$ \\
\hline 2,9 & $-37,972$ \\
\hline 3,1 & $-38,108$ \\
\hline 3,3 & $-38,011$ \\
\hline 3,5 & $-38,011$ \\
\hline 3,7 & $-38,157$ \\
\hline 3,9 & $-38,235$ \\
\hline 4,1 & $-37,953$ \\
\hline 4,3 & $-23,628$ \\
\hline 4,5 & $-11,98$ \\
\hline 4,7 & $-10,005$ \\
\hline 4,9 & $-8,58$ \\
\hline 5,1 & $-7,451$ \\
\hline 5,3 & $-6,474$ \\
\hline 5,5 & $-5,743$ \\
\hline 5,7 & $-5,244$ \\
\hline 5,9 & $-4,76$ \\
\hline 6,1 & $-4,439$ \\
\hline 6,3 & $-4,045$ \\
\hline 6,5 & $-3,869$ \\
\hline 6,7 & $-3,705$ \\
\hline 6,9 & $-3,558$ \\
\hline 7,1 & $-3,31$ \\
\hline 7,3 & $-3,214$ \\
\hline 7,5 & $-3,04$ \\
\hline 7,7 & $-2,849$ \\
\hline 7,9 & $-2,682$ \\
\hline 8,1 & $-2,548$ \\
\hline
\end{tabular}

\begin{tabular}{|c|c|}
\hline 8,3 & $-2,42$ \\
\hline 8,5 & $-2,27$ \\
\hline 8,7 & $-2,236$ \\
\hline 8,9 & $-2,181$ \\
\hline 9,1 & $-2,092$ \\
\hline 9,3 & $-2,07$ \\
\hline 9,5 & $-1,976$ \\
\hline 9,7 & $-1,943$ \\
\hline 9,9 & $-1,954$ \\
\hline 10,1 & $-1,893$ \\
\hline 10,3 & $-1,827$ \\
\hline 10,5 & $-1,722$ \\
\hline 10,7 & $-1,667$ \\
\hline 10,9 & $-1,656$ \\
\hline 11,1 & $-1,579$ \\
\hline 11,3 & $-1,496$ \\
\hline 11,5 & $-1,458$ \\
\hline 11,7 & $-1,392$ \\
\hline 11,9 & $-1,271$ \\
\hline 12,1 & $-1,271$ \\
\hline 12,3 & $-1,239$ \\
\hline 12,5 & $-1,184$ \\
\hline 12,7 & $-1,151$ \\
\hline 12,9 & $-1,053$ \\
\hline 13,1 & $-1,113$ \\
\hline 13,3 & $-1,047$ \\
\hline 13,5 & $-1,047$ \\
\hline 13,7 & $-1,036$ \\
\hline 13,9 & $-0,993$ \\
\hline 14,1 & $-0,862$ \\
\hline 14,3 & $-0,9$ \\
\hline 14,5 & $-0,9$ \\
\hline 14,7 & $-0,84$ \\
\hline 14,9 & $-0,971$ \\
\hline 15,1 & $-0,943$ \\
\hline
\end{tabular}


C.5 DT 2 - Dente tratado endodonticamente.

\begin{tabular}{|c|c|}
\hline DT & \\
\hline Tempo (s) & $\begin{array}{c}\text { Temperatura } \\
(\Delta \mathrm{T})\end{array}$ \\
\hline 0,2 & $-10,595$ \\
\hline 0,4 & $-9,741$ \\
\hline 0,6 & $-7,483$ \\
\hline 0,8 & $-5,848$ \\
\hline 1 & $-4,521$ \\
\hline 1,2 & $-3,879$ \\
\hline 1,4 & $-3,236$ \\
\hline 1,6 & $-2,825$ \\
\hline 1,8 & $-2,444$ \\
\hline 2 & $-2,128$ \\
\hline 2,2 & $-1,939$ \\
\hline 2,4 & $-1,791$ \\
\hline 2,6 & $-1,563$ \\
\hline 2,8 & $-1,416$ \\
\hline 3 & $-1,37$ \\
\hline 3,2 & $-1,268$ \\
\hline 3,4 & $-1,014$ \\
\hline 3,6 & $-0,828$ \\
\hline 3,8 & $-0,834$ \\
\hline 4 & $-0,806$ \\
\hline 4,2 & $-0,896$ \\
\hline 4,4 & $-0,867$ \\
\hline 4,6 & $-0,761$ \\
\hline 4,8 & $-0,614$ \\
\hline 5 & $-0,575$ \\
\hline 5,2 & $-0,514$ \\
\hline 5,4 & $-0,643$ \\
\hline 5,6 & $-0,682$ \\
\hline 5,8 & $-0,687$ \\
\hline 6 & $-0,744$ \\
\hline 6,2 & $-0,643$ \\
\hline 6,4 & $-0,586$ \\
\hline 6,6 & $-0,57$ \\
\hline 6,8 & $-0,553$ \\
\hline 7 & $-0,452$ \\
\hline 7,2 & $-0,43$ \\
\hline 7,4 & $-0,497$ \\
\hline 7,6 & $-0,654$ \\
\hline 7,8 & $-0,581$ \\
\hline 8 & $-0,519$ \\
\hline 8,2 & $-0,519$ \\
\hline 8,4 & $-0,525$ \\
\hline 8,6 & $-0,43$ \\
\hline 8,8 & $-0,402$ \\
\hline 9 & $-0,346$ \\
\hline 9,2 & $-0,334$ \\
\hline 9,4 & $-0,385$ \\
\hline 9,6 & $-0,396$ \\
\hline
\end{tabular}

\begin{tabular}{|c|c|}
\hline 9,8 & $-0,329$ \\
\hline 10 & $-0,351$ \\
\hline 10,2 & $-0,239$ \\
\hline 10,4 & $-0,145$ \\
\hline 10,6 & $-0,15$ \\
\hline 10,8 & $-0,145$ \\
\hline 11 & $-0,1$ \\
\hline 11,2 & $-0,016$ \\
\hline 11,4 & $1,07 \mathrm{E}-14$ \\
\hline 11,6 & $-0,072$ \\
\hline 11,8 & $-0,055$ \\
\hline 12 & $-0,139$ \\
\hline 12,2 & $-0,189$ \\
\hline 12,4 & $-0,139$ \\
\hline 12,6 & $-0,167$ \\
\hline 12,8 & $-0,262$ \\
\hline 13 & $-0,279$ \\
\hline 13,2 & $-0,374$ \\
\hline 13,4 & $-0,267$ \\
\hline 13,6 & $-0,072$ \\
\hline 13,8 & $-0,061$ \\
\hline 14 & $-0,028$ \\
\hline 14,2 & $-0,005$ \\
\hline 14,4 & $-0,05$ \\
\hline 14,6 & $-0,028$ \\
\hline 14,8 & 0,023 \\
\hline 15 & $-0,044$ \\
\hline 15,2 & 1,07 \\
\hline & \\
\hline
\end{tabular}


APÊNDICE D - Valores originais de variação de temperatura $(\Delta T)$ obtidos nas tomadas de estimulação com gás refrigerante sem a utilização de isolamento absoluto, expressos em Graus Celsius.

D.1 PV 1 - Dente portador de polpa vital

\begin{tabular}{|c|c|}
\hline PV & \\
\hline Tempo (s) & Temperatura $(\Delta \mathrm{T})$ \\
\hline 0,2 & $-36,02$ \\
\hline 0,4 & $-12,337$ \\
\hline 0,6 & $-11,109$ \\
\hline 0,8 & $-10,093$ \\
\hline 1 & $-9,194$ \\
\hline 1,2 & $-8,411$ \\
\hline 1,4 & $-7,76$ \\
\hline 1,6 & $-7,183$ \\
\hline 1,8 & $-6,671$ \\
\hline 2 & $-6,163$ \\
\hline 2,2 & $-5,73$ \\
\hline 2,4 & $-5,389$ \\
\hline 2,6 & $-5,068$ \\
\hline 2,8 & $-4,724$ \\
\hline 3 & $-4,506$ \\
\hline 3,2 & $-4,318$ \\
\hline 3,4 & $-4,095$ \\
\hline 3,6 & $-3,855$ \\
\hline 3,8 & $-3,61$ \\
\hline 4 & $-3,412$ \\
\hline 4,2 & $-3,239$ \\
\hline 4,4 & $-3,094$ \\
\hline 4,6 & $-2,95$ \\
\hline 4,8 & $-2,829$ \\
\hline 5 & $-2,742$ \\
\hline 5,2 & $-2,639$ \\
\hline 5,4 & $-2,547$ \\
\hline 5,6 & $-2,524$ \\
\hline 5,8 & $-2,455$ \\
\hline 6 & $-2,404$ \\
\hline 6,2 & $-2,307$ \\
\hline 6,4 & $-2,25$ \\
\hline 6,6 & $-2,141$ \\
\hline 6,8 & $-2,01$ \\
\hline 7 & $-1,925$ \\
\hline 7,2 & $-1,856$ \\
\hline 7,4 & $-1,777$ \\
\hline 7,6 & $-1,72$ \\
\hline 7,8 & $-1,669$ \\
\hline 8 & $-1,635$ \\
\hline 8,2 & $-1,624$ \\
\hline 8,4 & $-1,618$ \\
\hline 8,6 & $-1,573$ \\
\hline 8,8 & $-1,522$ \\
\hline 9 & $-1,437$ \\
\hline
\end{tabular}

\begin{tabular}{|c|c|}
\hline 9,2 & $-1,386$ \\
\hline 9,4 & $-1,392$ \\
\hline 9,6 & $-1,381$ \\
\hline 9,8 & $-1,313$ \\
\hline 10 & $-1,257$ \\
\hline 10,2 & $-1,206$ \\
\hline 10,4 & $-1,11$ \\
\hline 10,6 & $-1,065$ \\
\hline 10,8 & $-1,06$ \\
\hline 11 & $-0,976$ \\
\hline 11,2 & $-0,987$ \\
\hline 11,4 & $-0,925$ \\
\hline 11,6 & $-0,942$ \\
\hline 11,8 & $-0,936$ \\
\hline 12 & $-0,936$ \\
\hline 12,2 & $-0,964$ \\
\hline 12,4 & $-0,947$ \\
\hline 12,6 & $-0,97$ \\
\hline 12,8 & $-0,998$ \\
\hline 13 & $-0,964$ \\
\hline 13,2 & $-0,964$ \\
\hline 13,4 & $-0,953$ \\
\hline 13,6 & $-0,964$ \\
\hline 13,8 & $-0,959$ \\
\hline 14 & $-0,908$ \\
\hline 14,2 & $-0,891$ \\
\hline 14,4 & $-0,891$ \\
\hline 14,6 & $-0,863$ \\
\hline 14,8 & $-0,847$ \\
\hline 15 & $-0,869$ \\
\hline
\end{tabular}


D.2 PV 2 - Dente portador de polpa vital.

\begin{tabular}{|c|c|}
\hline PV & \\
\hline Tempo (s) & Temperatura $(\Delta T)$ \\
\hline 0,2 & 0 \\
\hline 0,4 & $-0,011$ \\
\hline 0,6 & 0,16 \\
\hline 0,8 & 0,457 \\
\hline 1 & 0,407 \\
\hline 1,2 & 0,407 \\
\hline 1,4 & 0,253 \\
\hline 1,6 & 0,275 \\
\hline 1,8 & 0,341 \\
\hline 2 & 0,314 \\
\hline 2,2 & 0,418 \\
\hline 2,4 & 0,511 \\
\hline 2,6 & $-34,122$ \\
\hline 2,8 & $-35,552$ \\
\hline 3 & $-30,642$ \\
\hline 3,2 & $-5,916$ \\
\hline 3,4 & $-3,54$ \\
\hline 3,6 & $-2,37$ \\
\hline 3,8 & $-1,594$ \\
\hline 4 & $-1,083$ \\
\hline 4,2 & $-0,787$ \\
\hline 4,4 & $-0,587$ \\
\hline 4,6 & $-0,542$ \\
\hline 4,8 & $-0,293$ \\
\hline 5 & $-0,348$ \\
\hline
\end{tabular}

\begin{tabular}{|c|c|}
\hline 5,2 & $-0,304$ \\
\hline 5,4 & $-0,232$ \\
\hline 5,6 & $-0,204$ \\
\hline 5,8 & $-0,027$ \\
\hline 6 & 0,061 \\
\hline 6,2 & $-0,143$ \\
\hline 6,4 & 0,072 \\
\hline 6,6 & 0,127 \\
\hline 6,8 & 0,193 \\
\hline 7 & $-0,055$ \\
\hline 7,2 & 0,072 \\
\hline 7,4 & 0,088 \\
\hline 7,6 & 0,149 \\
\hline 7,8 & 0,044 \\
\hline 8 & 0,105 \\
\hline 8,2 & $-0,11$ \\
\hline 8,4 & 0,088 \\
\hline 8,6 & 0,088 \\
\hline 8,8 & 0,083 \\
\hline 9 & $-0,094$ \\
\hline 9,2 & $-0,077$ \\
\hline 9,4 & $-0,088$ \\
\hline 9,6 & $-0,127$ \\
\hline 9,8 & 0 \\
\hline 10 & $-0,033$ \\
\hline 10,2 & 0,292 \\
\hline 10,4 & 0,281 \\
\hline
\end{tabular}


D.3 PV 3 - Dente portador de polpa vital.

\begin{tabular}{|c|c|}
\hline PV & \\
\hline $\begin{array}{c}\text { Tempo } \\
\text { (s) }\end{array}$ & $\begin{array}{c}\text { Temperatura } \\
(\Delta \mathrm{T})\end{array}$ \\
\hline$-4,8$ & 0 \\
\hline$-4,6$ & 0,097 \\
\hline$-4,4$ & 0,086 \\
\hline$-4,2$ & $-0,01$ \\
\hline-4 & 0,027 \\
\hline$-3,8$ & $-0,005$ \\
\hline$-3,6$ & 0,209 \\
\hline$-3,4$ & 0,209 \\
\hline$-3,2$ & 0,279 \\
\hline-3 & 0,193 \\
\hline$-2,8$ & 0,14 \\
\hline$-2,6$ & 0,161 \\
\hline$-2,4$ & 0,183 \\
\hline$-2,2$ & 0,167 \\
\hline-2 & 0,027 \\
\hline$-1,8$ & 0,022 \\
\hline$-1,6$ & $-0,01$ \\
\hline$-1,4$ & $-0,107$ \\
\hline$-1,2$ & $-0,059$ \\
\hline-1 & 0,027 \\
\hline$-0,8$ & $-0,016$ \\
\hline$-0,6$ & 0,075 \\
\hline$-0,4$ & 0,049 \\
\hline$-0,2$ & 0,022 \\
\hline 0 & 0,075 \\
\hline 0,2 & 0,167 \\
\hline 0,4 & $-28,487$ \\
\hline 0,6 & $-37,88$ \\
\hline 0,8 & $-37,678$ \\
\hline 1 & $-37,209$ \\
\hline 1,2 & $-37,649$ \\
\hline 1,4 & $-37,505$ \\
\hline 1,6 & $-9,027$ \\
\hline 1,8 & $-5,485$ \\
\hline 2 & $-3,72$ \\
\hline 2,2 & $-2,784$ \\
\hline 2,4 & $-2,157$ \\
\hline 2,6 & $-1,716$ \\
\hline 2,8 & $-1,447$ \\
\hline 3 & $-1,141$ \\
\hline 3,2 & $-1,081$ \\
\hline
\end{tabular}

\begin{tabular}{|c|c|}
\hline 3,4 & $-1,038$ \\
\hline 3,6 & $-1,005$ \\
\hline 3,8 & $-0,929$ \\
\hline 4 & $-0,907$ \\
\hline 4,2 & $-0,82$ \\
\hline 4,4 & $-0,728$ \\
\hline 4,6 & $-0,604$ \\
\hline 4,8 & $-0,544$ \\
\hline 5 & $-0,517$ \\
\hline 5,2 & $-0,49$ \\
\hline 5,4 & $-0,506$ \\
\hline 5,6 & $-0,544$ \\
\hline 5,8 & $-0,501$ \\
\hline 6 & $-0,593$ \\
\hline 6,2 & $-0,566$ \\
\hline 6,4 & $-0,522$ \\
\hline 6,6 & $-0,522$ \\
\hline 6,8 & $-0,468$ \\
\hline 7 & $-0,414$ \\
\hline 7,2 & $-0,339$ \\
\hline 7,4 & $-0,328$ \\
\hline 7,6 & $-0,355$ \\
\hline 7,8 & $-0,29$ \\
\hline 8 & $-0,199$ \\
\hline 8,2 & $-0,161$ \\
\hline 8,4 & $-0,269$ \\
\hline 8,6 & $-0,145$ \\
\hline 8,8 & $-0,188$ \\
\hline 9 & $-0,113$ \\
\hline 9,2 & $-0,226$ \\
\hline 9,4 & $-0,474$ \\
\hline 9,6 & $-0,409$ \\
\hline 9,8 & $-0,387$ \\
\hline 10 & $-0,333$ \\
\hline 10,2 & $-0,274$ \\
\hline 10,4 & $-0,312$ \\
\hline 10,6 & $-0,387$ \\
\hline 10,8 & $-0,49$ \\
\hline 11 & $-0,549$ \\
\hline 11,2 & $-0,549$ \\
\hline 11,4 & $-0,522$ \\
\hline 11,6 & $-0,436$ \\
\hline
\end{tabular}


D.4 DT 1 - Dente tratado endodonticamente.

\begin{tabular}{|c|c|}
\hline DT & \\
\hline Tempo (s) & Temperatura $(\Delta T)$ \\
\hline 0,2 & 0 \\
\hline 0,4 & 0,066 \\
\hline 0,6 & 0,094 \\
\hline 0,8 & 0,149 \\
\hline 1 & 0,177 \\
\hline 1,2 & 0,155 \\
\hline 1,4 & 0,182 \\
\hline 1,6 & $-11,606$ \\
\hline 1,8 & $-35,459$ \\
\hline 2 & $-36,708$ \\
\hline 2,2 & $-36,104$ \\
\hline 2,4 & $-36,289$ \\
\hline 2,6 & $-36,875$ \\
\hline 2,8 & $-36,905$ \\
\hline 3 & $-36,924$ \\
\hline 3,2 & $-36,708$ \\
\hline 3,4 & $-36,855$ \\
\hline 3,6 & $-37,171$ \\
\hline 3,8 & $-37,161$ \\
\hline 4 & $-37,121$ \\
\hline 4,2 & $-36,63$ \\
\hline 4,4 & $-12,238$ \\
\hline 4,6 & $-10,136$ \\
\hline 4,8 & $-8,566$ \\
\hline 5 & $-7,305$ \\
\hline 5,2 & $-6,384$ \\
\hline 5,4 & $-5,594$ \\
\hline 5,6 & $-5,007$ \\
\hline 5,8 & $-4,496$ \\
\hline 6 & $-4,104$ \\
\hline 6,2 & $-3,888$ \\
\hline 6,4 & $-3,622$ \\
\hline 6,6 & $-3,465$ \\
\hline 6,8 & $-3,258$ \\
\hline 7 & $-3,027$ \\
\hline 7,2 & $-2,844$ \\
\hline 7,4 & $-2,672$ \\
\hline 7,6 & $-2,427$ \\
\hline 7,8 & $-2,296$ \\
\hline 8 & $-2,216$ \\
\hline 8,2 & $-2,057$ \\
\hline 8,4 & $-1,91$ \\
\hline 8,6 & $-1,859$ \\
\hline 8,8 & $-1,853$ \\
\hline 9 & $-1,814$ \\
\hline 9,2 & $-1,803$ \\
\hline 9,4 & $-1,723$ \\
\hline 9,6 & $-1,571$ \\
\hline
\end{tabular}

\begin{tabular}{|c|c|}
\hline 9,8 & $-1,419$ \\
\hline 10 & $-1,301$ \\
\hline 10,2 & $-1,178$ \\
\hline 10,4 & $-1,369$ \\
\hline 10,6 & $-1,464$ \\
\hline 10,8 & $-1,526$ \\
\hline 11 & $-1,481$ \\
\hline 11,2 & $-1,402$ \\
\hline 11,4 & $-1,436$ \\
\hline 11,6 & $-1,453$ \\
\hline 11,8 & $-1,459$ \\
\hline 12 & $-1,397$ \\
\hline 12,2 & $-1,251$ \\
\hline 12,4 & $-1,1$ \\
\hline 12,6 & $-0,971$ \\
\hline 12,8 & $-0,971$ \\
\hline 13 & $-0,904$ \\
\hline 13,2 & $-0,882$ \\
\hline 13,4 & $-0,765$ \\
\hline 13,6 & $-0,681$ \\
\hline 13,8 & $-0,653$ \\
\hline 14 & $-0,614$ \\
\hline 14,2 & $-0,564$ \\
\hline 14,4 & $-0,487$ \\
\hline 14,6 & $-0,609$ \\
\hline 14,8 & $-0,648$ \\
\hline 15 & $-0,592$ \\
\hline & \\
\hline
\end{tabular}


D.5 DT 2 - Dente tratado endodonticamente.

\begin{tabular}{|c|c|}
\hline DT & \\
\hline Tempo (s) & Temperatura $(\Delta \mathbf{T})$ \\
\hline 0,2 & 0 \\
\hline 0,4 & 0 \\
\hline 0,6 & $-0,005$ \\
\hline 0,8 & 0,127 \\
\hline 1 & $-0,055$ \\
\hline 1,2 & $-37,602$ \\
\hline 1,4 & $-38,071$ \\
\hline 1,6 & $-16,134$ \\
\hline 1,8 & $-9,782$ \\
\hline 2 & $-7,017$ \\
\hline 2,2 & $-5,374$ \\
\hline 2,4 & $-4,292$ \\
\hline 2,6 & $-3,612$ \\
\hline 2,8 & $-3,133$ \\
\hline 3 & $-2,681$ \\
\hline 3,2 & $-2,384$ \\
\hline 3,4 & $-2,163$ \\
\hline 3,6 & $-1,885$ \\
\hline 3,8 & $-1,846$ \\
\hline 4 & $-1,66$ \\
\hline 4,2 & $-1,44$ \\
\hline 4,4 & $-1,423$ \\
\hline 4,6 & $-1,362$ \\
\hline 4,8 & $-1,188$ \\
\hline 5 & $-1,255$ \\
\hline & \\
\hline
\end{tabular}

\begin{tabular}{|c|c|}
\hline 5,2 & $-1,166$ \\
\hline 5,4 & $-1,043$ \\
\hline 5,6 & $-1,015$ \\
\hline 5,8 & $-1,065$ \\
\hline 6 & $-0,903$ \\
\hline 6,2 & $-1,21$ \\
\hline 6,4 & $-0,942$ \\
\hline 6,6 & $-0,691$ \\
\hline 6,8 & $-0,87$ \\
\hline 7 & $-0,914$ \\
\hline 7,2 & $-0,959$ \\
\hline 7,4 & $-0,903$ \\
\hline 7,6 & $-0,842$ \\
\hline 7,8 & $-0,758$ \\
\hline 8 & $-0,736$ \\
\hline 8,2 & $-0,769$ \\
\hline 8,4 & $-0,48$ \\
\hline 8,6 & $-0,403$ \\
\hline 8,8 & $-0,842$ \\
\hline 9 & $-0,608$ \\
\hline 9,2 & $-0,825$ \\
\hline 9,4 & $-0,686$ \\
\hline 9,6 & $-0,519$ \\
\hline 9,8 & $-0,336$ \\
\hline 10 & $-0,453$ \\
\hline 10,2 & $-0,386$ \\
\hline 10,4 & $-0,469$ \\
\hline & \\
\hline
\end{tabular}

